\title{
Identification of Nicotiana benthamiana microRNAs and their targets using high throughput sequencing and degradome analysis
}

Ivett Baksa, Tibor Nagy, Endre Barta, Zoltán Havelda, Éva Várallyay, Dániel Silhavy, József Burgyán and György Szittya ${ }^{*}$

\begin{abstract}
Background: Nicotiana benthamiana is a widely used model plant species for research on plant-pathogen interactions as well as other areas of plant science. It can be easily transformed or agroinfiltrated, therefore it is commonly used in studies requiring protein localization, interaction, or plant-based systems for protein expression and purification. To discover and characterize the miRNAs and their cleaved target mRNAs in N. benthamiana, we sequenced small RNA transcriptomes and degradomes of two $\mathrm{N}$. benthamiana accessions and validated them by Northern blots.

Results: We used a comprehensive molecular approach to detect and to experimentally validate $N$. benthamiana miRNAs and their target mRNAs from various tissues. We identified 40 conserved miRNA families and 18 novel microRNA candidates and validated their target mRNAs with a genomic scale approach. The accumulation of thirteen novel miRNAs was confirmed by Northern blot analysis. The conserved and novel miRNA targets were found to be involved in various biological processes including transcription, RNA binding, DNA modification, signal transduction, stress response and metabolic process. Among the novel miRNA targets we found the mRNA of REPRESSOR OF SILENCING (ROS1). Regulation of ROS1 by a miRNA provides a new regulatory layer to reinforce transcriptional gene silencing by a post-transcriptional repression of ROS1 activity.

Conclusions: The identified conserved and novel miRNAs along with their target mRNAs also provides a tissue specific atlas of known and new miRNA expression and their cleaved target mRNAs of $N$. benthamiana. Thus this study will serve as a valuable resource to the plant research community that will be beneficial well into the future.
\end{abstract}

Keywords: Nicotiana benthamiana, microRNA, Non-coding RNAs, Small RNA, Degradome, High throughput sequencing

\section{Background}

Nicotiana benthamiana is a widely used model plant species for research on plant-pathogen interactions as well as other areas of plant science. It is particularly popular among plant virologist as it is susceptible to a large number of different plant viruses. It is also widely used in studies requiring protein localization, interaction, or plant-based systems for protein expression and purification. In addition, its susceptibility to pathogens has been

\footnotetext{
*Correspondence: szittya@abc.hu

Institute of Plant Biotechnology, National Agricultural Research and Innovation Centre, Agricultural Biotechnology Institute, Szent-Györgyi Albert ut 4, H-2100 Gödöllö, Hungary
}

used to transiently express proteins, using either engineered viruses or syringe-infiltration of Agrobacterium tumefaciens $[1,2]$. The syringe-infiltration method proved to be extremely powerful tool to identify and characterize many viral silencing suppressor proteins [3], pathogens effector proteins [4] and also components of the plant nonsense-mediated mRNA decay system [5].

$N$. benthamiana is an herbaceous plant endemic to Australia [2], belonging to the Suaveolentes section of the Nicotiana genus of Solanaceae family. $N$. benthamiana is an allotetraploid species with 19 chromosome pairs, resulting from the hybridization of two unknown progenitors. The estimated genome size of $N$. benthamiana is

\section{Biomed Central}

(c) 2015 Baksa et al. Open Access This article is distributed under the terms of the Creative Commons Attribution 4.0 International License (http://creativecommons.org/licenses/by/4.0/), which permits unrestricted use, distribution, and reproduction in any medium, provided you give appropriate credit to the original author(s) and the source, provide a link to the Creative Commons license, and indicate if changes were made. The Creative Commons Public Domain Dedication waiver (http://creativecommons.org/publicdomain/zero/1.0/) applies to the data made available in this article, unless otherwise stated. 
3 GB [2]. The draft genome sequence of the N. benthamiana $\mathrm{Nb}-1$ accession has been published recently [1]. The origins of the $N$. benthamiana accessions used for research are generally not known. However it has been suggested that only a single accession of $N$. benthamiana, or a collection of closely related accessions, are being used by the plant research community today, since they are very similar in both susceptibility to pathogens and also in phenotype [2]. The genomes of economically important close relatives of $N$. benthamiana, such as potato (Solanum tuberosum), tomato (Solanum lycopersicum) and pepper (Capsicum annuum), genomes have been also sequenced recently [6-9]. These species has either smaller or very similar genome size to $N$. benthamiana. The Potato (Solanum tuberosum) genome size is $844 \mathrm{Mb}$ [6], the tomato (Solanum lycopersicum) genome size is approximately $900 \mathrm{Mb}$ [8] and both species has twelve chromosomes. Other economically important members of the Solanaceae family is the pepper and the eggplant. The widely cultivated $C$. annuum accession Zunla-1 genome size is estimated to be $3.26 \mathrm{~Gb}$ [9], while the genome size of the eggplant is approximately $833.1 \mathrm{Mb}$ [10].

Gene expression is regulated at several layers to ensure optimal spatial and temporal accumulation of proteins. RNA silencing is an evolutionarily conserved, important gene expression regulator of various cellular processes in eukaryotes, whereby 21-24 nt small RNAs (sRNAs) direct silencing of endogenous genes or pathogens. Plant sRNAs have two major categories based on their biogenesis: small interfering RNA (siRNA) processed from perfectly double stranded RNA; and microRNA (miRNA) derived from single stranded RNA transcripts that form imperfectly double-stranded stem loop precursor structures [11]. MIR genes encode the precursor transcripts which are cleaved into miRNAs by Dicer-like 1 (DCL-1), and subsequently loaded into an RNA Induced Silencing Complex (RISC), containing an ARGONAUTE (AGO) protein. miRNA guided RISCs are able to inhibit expression of genes with at least partial homology to the miRNA by either transcript cleavage or translational arrest [12]. miRNAs have important roles in different cellular processes including developmental/ physiological processes and abiotic/biotic stress $[13,14]$. miRNAs are classified into families, whereby miRNAs with the same or very similar sequences are grouped into the same family. It has been shown that only a small number of miRNA families are present across phylogenetically distant species [15-17]. The majority of plant miRNAs are evolutionarily young and are only present in one to few species and it is likely that MIR loci in plant genomes are in a constant dynamic evolutionary state $[15,16]$.

Although the draft genome of $N$. benthamiana is available and transcriptome-wide expression studies have been reported [1,18-20], the miRNA profile of $N$. benthamiana has not been analysed. In this study, we used a comprehensive molecular and bioinformatic approach to detect and experimentally validate miRNAs and their target mRNAs from five different tissues of two $N$. benthamiana lines (the $N$. benthamiana plant, which is used in our laboratory and the sequenced $\mathrm{Nb}-1$ accession). In our study, we used Illumina sequencing to identify small RNAs, their cleaved target mRNAs followed by Northern blot validation of the miRNAs. Furthermore, we examined cleaved miRNA targets from five different tissues of two aforementioned $N$. benthamiana accessions. We identified 40 conserved and 18 novel microRNAs and validated their target mRNAs in $N$. benthamiana with a genomic scale method. The targets were found to be involved in various biological processes including transcription, RNA binding, DNA modification, signal transduction, stress response and metabolic processes. We anticipate that this study will serve as a valuable resource of $N$. benthamiana miRNAs and their validated target mRNAs to the whole plant research community.

\section{Results and discussion}

High-throughput sequencing of $N$. benthamiana small RNAs

To identify and comprehensively describe the expression of endogenous sRNAs in $N$. benthamiana, sRNAs containing $5^{\prime}$-phosphate and $3^{\prime}-\mathrm{OH}$ (likely to be a products of Dicer-like proteins) were cloned from roots, stems, leaves, flowers and small seedlings (containing both root tissue and aerial parts) of $N$. benthamiana plants. The libraries were then sequenced by high-throughput Illumina sequencing. By using biological replicates of five tissues, ten cDNA libraries were made from the $N$. benthamiana line that is used in our laboratory. To compare the sRNA profile of our $N$. benthamiana line and the line, which has been sequenced ( $\mathrm{Nb}-1$ accession), two additional sRNA libraries were prepared and sequenced from the leaves and small seedlings of Nb-1 accession. These twelve cDNA libraries yielded approximately 90 million reads. Sequences flanked by the $5^{\prime}$ and 3' Solexa adaptors, with a minimum and maximum length of 16 and $28 \mathrm{nt}$, respectively, were compared with the draft $N$. benthamiana genome sequences. More than 15 million non-redundant reads were perfectly matched to at least one locus, and were analysed further (Table 1). The size distribution of sequence reads showed that the majority of sRNAs in our libraries belonged to the $24 \mathrm{nt}$ size class and it was followed by the 21-22 nt size classes (Fig. 1). Our sequence data are in agreement with previous observations which show that in plants, this 24 nt size class is the overall most abundant class of sRNAs [15].

\section{Identification of known and conserved miRNAs in $N$. benthaniana}

miRNAs are a well-studied class of regulatory sRNAs. They are present in all plant species studied so far and 
Table 1 High-throughput sequencing statistics of N. benthamiana sRNAs

\begin{tabular}{|c|c|c|c|c|c|c|c|c|c|c|c|}
\hline & & \multicolumn{2}{|c|}{ Redundant } & \multicolumn{2}{|c|}{ Non-redundant } & & & \multicolumn{2}{|c|}{ Redundant } & \multicolumn{2}{|c|}{ Non-redundant } \\
\hline & & Reads & $\begin{array}{l}\text { Matching } N \text {. } \\
\text { benthamiana genome }\end{array}$ & Reads & $\begin{array}{l}\text { Matching } N \text {. } \\
\text { benthamiana genome }\end{array}$ & & & Reads & $\begin{array}{l}\text { Matching } N \text {. } \\
\text { benthamiana genome }\end{array}$ & Reads & $\begin{array}{l}\text { Matching } N \text {. } \\
\text { benthamiana genome }\end{array}$ \\
\hline \multirow[t]{5}{*}{$\begin{array}{l}\text { Seedling } \\
1\end{array}$} & Raw reads & $\begin{array}{l}4353 \\
615\end{array}$ & & & & Stem 1 & Raw reads & $\begin{array}{l}2673 \\
839\end{array}$ & & & \\
\hline & Adaptor removed & $\begin{array}{l}3192 \\
563\end{array}$ & & $\begin{array}{l}1106 \\
502\end{array}$ & & & Adaptor removed & $\begin{array}{l}2468 \\
386\end{array}$ & & $\begin{array}{l}858 \\
314\end{array}$ & \\
\hline & $\begin{array}{l}\text { Filter by sequence } \\
\text { properties }\end{array}$ & $\begin{array}{l}3187 \\
558\end{array}$ & & $\begin{array}{l}1102 \\
305\end{array}$ & & & $\begin{array}{l}\text { Filter by sequence } \\
\text { properties }\end{array}$ & $\begin{array}{l}2464 \\
474\end{array}$ & & $\begin{array}{l}854 \\
744\end{array}$ & \\
\hline & t/rRNA removed & $\begin{array}{l}3034 \\
009\end{array}$ & 2791655 & $\begin{array}{l}1085 \\
271\end{array}$ & 942175 & & t/rRNA removed & $\begin{array}{l}2404 \\
489\end{array}$ & 2205954 & $\begin{array}{l}846 \\
701\end{array}$ & 746712 \\
\hline & $\begin{array}{l}\text { Match known } \\
\text { miRNAs }\end{array}$ & $\begin{array}{l}262 \\
998\end{array}$ & 259394 & 1531 & 792 & & $\begin{array}{l}\text { Match known } \\
\text { miRNAs }\end{array}$ & $\begin{array}{l}121 \\
361\end{array}$ & 119819 & 1376 & 860 \\
\hline \multirow[t]{5}{*}{$\begin{array}{l}\text { Seedling } \\
2\end{array}$} & Raw reads & $\begin{array}{l}13565 \\
620\end{array}$ & & & & Stem 2 & Raw reads & $\begin{array}{l}13390 \\
095\end{array}$ & & & \\
\hline & Adaptor removed & $\begin{array}{l}9931 \\
841\end{array}$ & & $\begin{array}{l}1048 \\
202\end{array}$ & & & Adaptor removed & $\begin{array}{l}12682 \\
160\end{array}$ & & $\begin{array}{l}3280 \\
430\end{array}$ & \\
\hline & $\begin{array}{l}\text { Filter by sequence } \\
\text { properties }\end{array}$ & $\begin{array}{l}9916 \\
497\end{array}$ & & $\begin{array}{l}1036 \\
381\end{array}$ & & & $\begin{array}{l}\text { Filter by sequence } \\
\text { properties }\end{array}$ & $\begin{array}{l}12662 \\
117\end{array}$ & & $\begin{array}{l}3263 \\
087\end{array}$ & \\
\hline & t/rRNA removed & $\begin{array}{l}9461 \\
135\end{array}$ & 8656790 & $\begin{array}{l}1016 \\
371\end{array}$ & 841123 & & t/rRNA removed & $\begin{array}{l}12195 \\
396\end{array}$ & 11213510 & $\begin{array}{l}3246 \\
517\end{array}$ & 2773011 \\
\hline & $\begin{array}{l}\text { Match known } \\
\text { miRNAs }\end{array}$ & $\begin{array}{l}1132 \\
848\end{array}$ & 1117758 & 2423 & 1030 & & $\begin{array}{l}\text { Match known } \\
\text { miRNAs }\end{array}$ & $\begin{array}{l}664 \\
082\end{array}$ & 654984 & 3455 & 1969 \\
\hline \multirow[t]{5}{*}{ Root 1} & Raw reads & $\begin{array}{l}4416 \\
396\end{array}$ & & & & Flower 1 & Raw reads & $\begin{array}{l}17715 \\
434\end{array}$ & & & \\
\hline & Adaptor removed & $\begin{array}{l}3567 \\
326\end{array}$ & & $\begin{array}{l}673 \\
485\end{array}$ & & & Adaptor removed & $\begin{array}{l}15107 \\
462\end{array}$ & & $\begin{array}{l}4920 \\
011\end{array}$ & \\
\hline & $\begin{array}{l}\text { Filter by sequence } \\
\text { properties }\end{array}$ & $\begin{array}{l}3561 \\
838\end{array}$ & & $\begin{array}{l}669 \\
035\end{array}$ & & & $\begin{array}{l}\text { Filter by sequence } \\
\text { properties }\end{array}$ & $\begin{array}{l}15084 \\
084\end{array}$ & & $\begin{array}{l}4899 \\
263\end{array}$ & \\
\hline & $\mathrm{t} / \mathrm{rRNA}$ removed & $\begin{array}{l}3250 \\
883\end{array}$ & 2926826 & $\begin{array}{l}652 \\
495\end{array}$ & 553372 & & t/rRNA removed & $\begin{array}{l}14374 \\
989\end{array}$ & 13270386 & $\begin{array}{l}4872 \\
774\end{array}$ & 4186250 \\
\hline & $\begin{array}{l}\text { Match known } \\
\text { miRNAs }\end{array}$ & $\begin{array}{l}368 \\
908\end{array}$ & 363793 & 1557 & 827 & & $\begin{array}{l}\text { Match known } \\
\text { miRNAs }\end{array}$ & $\begin{array}{l}517 \\
965\end{array}$ & 510930 & 3461 & 2128 \\
\hline \multirow[t]{4}{*}{ Root 2} & Raw reads & $\begin{array}{l}6227 \\
488\end{array}$ & & & & Flower 2 & Raw reads & $\begin{array}{l}8784 \\
135\end{array}$ & & & \\
\hline & Adaptor removed & $\begin{array}{l}5472 \\
237\end{array}$ & & $\begin{array}{l}2020 \\
365\end{array}$ & & & Adaptor removed & $\begin{array}{l}8156 \\
033\end{array}$ & & $\begin{array}{l}2 \\
71814\end{array}$ & \\
\hline & $\begin{array}{l}\text { Filter by sequence } \\
\text { properties }\end{array}$ & $\begin{array}{l}5463 \\
791\end{array}$ & & $\begin{array}{l}2013 \\
081\end{array}$ & & & $\begin{array}{l}\text { Filter by sequence } \\
\text { properties }\end{array}$ & $\begin{array}{l}8143 \\
554\end{array}$ & & $\begin{array}{l}262 \\
570\end{array}$ & \\
\hline & $\mathrm{t} / \mathrm{rRNA}$ removed & $\begin{array}{l}5041 \\
719\end{array}$ & 4673608 & $\begin{array}{l}1992 \\
006\end{array}$ & 1746022 & & t/rRNA removed & $\begin{array}{l}7295 \\
596\end{array}$ & 6508891 & $\begin{array}{l}253 \\
399\end{array}$ & 185299 \\
\hline
\end{tabular}


Table 1 High-throughput sequencing statistics of N. benthamiana sRNAs (Continued)

\begin{tabular}{|c|c|c|c|c|c|c|c|c|c|c|c|}
\hline & $\begin{array}{l}\text { Match known } \\
\text { miRNAs }\end{array}$ & $\begin{array}{l}308 \\
179\end{array}$ & 304276 & 2402 & 1474 & & $\begin{array}{l}\text { Match known } \\
\text { miRNAs }\end{array}$ & $\begin{array}{l}817 \\
620\end{array}$ & 807317 & 1526 & 547 \\
\hline \multirow[t]{5}{*}{ Leaf 1} & Raw reads & $\begin{array}{l}4481 \\
051\end{array}$ & & & & Leaf ${ }^{B T I}$ & Raw reads & $\begin{array}{l}2646 \\
118\end{array}$ & & & \\
\hline & Adaptor removed & $\begin{array}{l}3752 \\
733\end{array}$ & & $\begin{array}{l}1675 \\
147\end{array}$ & & & Adaptor removed & $\begin{array}{l}2373 \\
816\end{array}$ & & $\begin{array}{l}445 \\
460\end{array}$ & \\
\hline & $\begin{array}{l}\text { Filter by sequence } \\
\text { properties }\end{array}$ & $\begin{array}{l}3746 \\
943\end{array}$ & & $\begin{array}{l}1670 \\
236\end{array}$ & & & $\begin{array}{l}\text { Filter by sequence } \\
\text { properties }\end{array}$ & $\begin{array}{l}2370 \\
062\end{array}$ & & $\begin{array}{l}442 \\
372\end{array}$ & \\
\hline & t/rRNA removed & $\begin{array}{l}3567 \\
987\end{array}$ & 3252343 & $\begin{array}{l}1644 \\
909\end{array}$ & 1440195 & & $\mathrm{t} / \mathrm{rRNA}$ removed & $\begin{array}{l}2277 \\
189\end{array}$ & 2092901 & $\begin{array}{l}433 \\
297\end{array}$ & 375749 \\
\hline & $\begin{array}{l}\text { Match known } \\
\text { miRNAs }\end{array}$ & $\begin{array}{l}258 \\
610\end{array}$ & 255179 & 2368 & 1502 & & $\begin{array}{l}\text { Match known } \\
\text { miRNAs }\end{array}$ & $\begin{array}{l}234 \\
022\end{array}$ & 231082 & 1025 & 489 \\
\hline \multirow[t]{5}{*}{ Leaf 2} & Raw reads & $\begin{array}{l}3801 \\
050\end{array}$ & & & & $\begin{array}{l}\text { Seedling } \\
\text { BTI }\end{array}$ & Raw reads & $\begin{array}{l}7874 \\
296\end{array}$ & & & \\
\hline & Adaptor removed & $\begin{array}{l}2925 \\
945\end{array}$ & & $\begin{array}{l}1149 \\
340\end{array}$ & & & Adaptor removed & $\begin{array}{l}7174 \\
326\end{array}$ & & $\begin{array}{l}2105 \\
046\end{array}$ & \\
\hline & $\begin{array}{l}\text { Filter by sequence } \\
\text { properties }\end{array}$ & $\begin{array}{l}2921 \\
408\end{array}$ & & $\begin{array}{l}1145 \\
456\end{array}$ & & & $\begin{array}{l}\text { Filter by sequence } \\
\text { properties }\end{array}$ & $\begin{array}{l}7163 \\
048\end{array}$ & & $\begin{array}{l}2095 \\
876\end{array}$ & \\
\hline & $\mathrm{t} / \mathrm{rRNA}$ removed & $\begin{array}{l}2834 \\
354\end{array}$ & 2596026 & $\begin{array}{l}1131 \\
710\end{array}$ & 982432 & & $\mathrm{t} / \mathrm{rRNA}$ removed & $\begin{array}{l}6906 \\
776\end{array}$ & 6088762 & $\begin{array}{l}2070 \\
845\end{array}$ & 287724 \\
\hline & $\begin{array}{l}\text { Match known } \\
\text { miRNAs }\end{array}$ & $\begin{array}{l}274 \\
028\end{array}$ & 270476 & 1434 & 737 & & $\begin{array}{l}\text { Match known } \\
\text { miRNAs }\end{array}$ & $\begin{array}{l}786 \\
266\end{array}$ & 423581 & 2205 & 113 \\
\hline
\end{tabular}




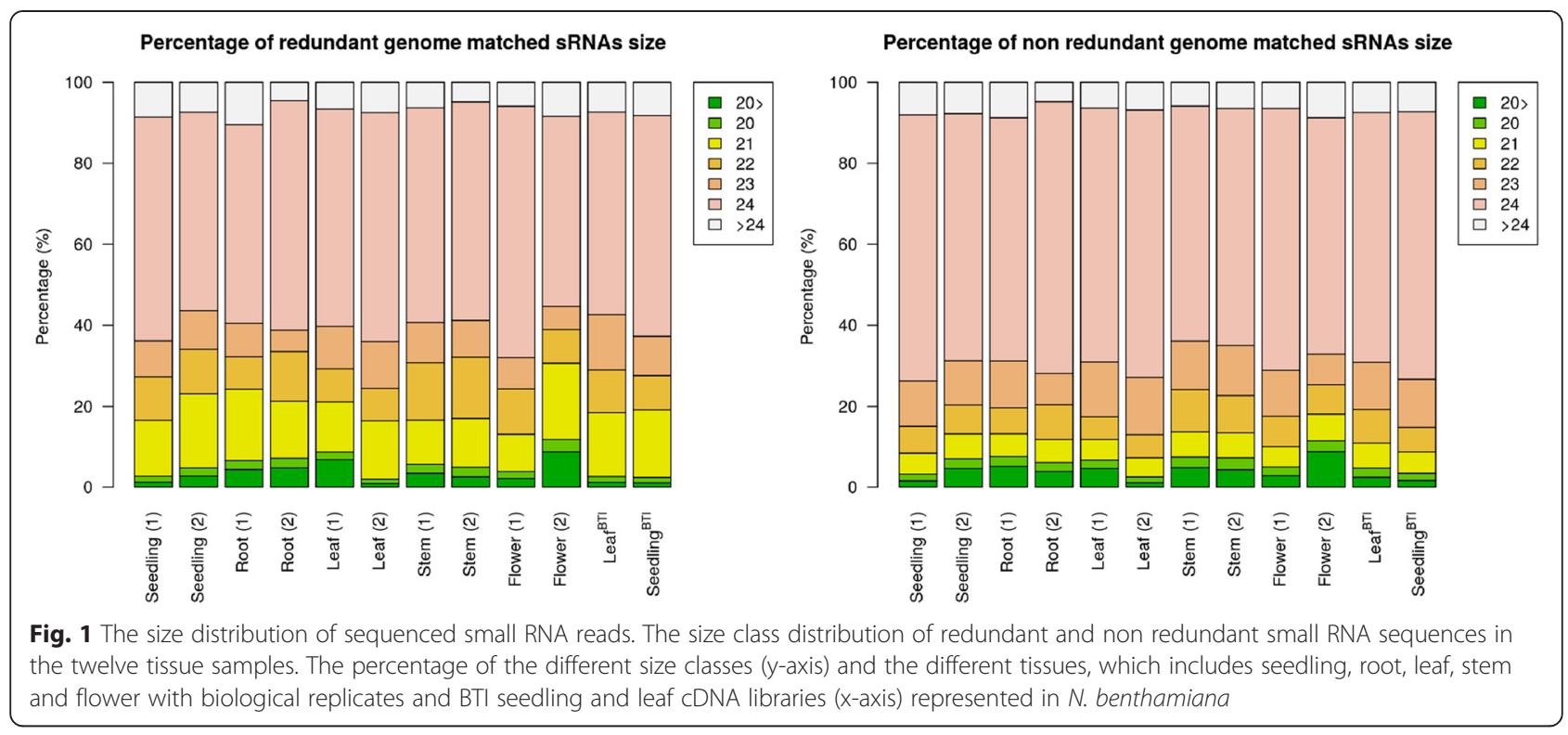

have important functions in plant development and stress responses. Conserved families of miRNAs were found in many plant species and analysis of data from highthroughput sequencing approaches identified eight deeply conserved miRNA families that are present in all embryophytes [16]. First we looked for known miRNAs by comparing our libraries to known miRNAs from other plant species and we identified 40 known or conserved miRNA families in the twelve sRNA libraries generated (Fig. 2, Additional file 1: Table S1). As expected, all of the deeply conserved miRNA families (miR156/157, miR159/319, miR160, miR165/166, miR171, miR408, miR390/391 and miR395) were present in our data sets (Fig. 2). We analysed the number of reads for conserved miRNAs and miR156, 159, 166, 168, 319, 396 and 403 were represented most frequently in the libraries (Fig. 2). As expected miRNA families expressed at very different levels and some miRNA families showed clear tissue-specific expression changes (Fig. 2). For example, the expression level of miR159 and miR166 families were high, while the expression of miR395 and miR399 families were similarly low in all tissues (Fig. 2). However, for miR395 and miR399 low expression is not surprising because their expression level is generally low under normal growth conditions as they are induced by sulphur or phosphate deficiency respectively $[21,22]$. A recent comprehensive atlas of miRNAs from 31 representative species across vascular plants identified 82 known miRNA families that were present across several terrestrial plants. These families formed eight groups depending on their distribution across lineages and species. miRNAs belonging to group 1 were ubiquitous and generally highly expressed across all terrestrial species (miR156, miR166, miR167, miR168 and miR172) while group 2 miRNA families were represented in all taxonomic lineages but could be absent or present at very low abundance levels in some species (miR158, miR159, miR160, miR162, miR164, miR169, miR171, miR319, miR390, miR393, miR394, miR396, miR397, miR529, miR535 and miR4414) [15]. Most of the group 1 and group 2 miRNA families were present in our data sets except the miR529, miR535 and miR4414 families (Fig. 2). Similar to our result, these three miRNA families were absent or their abundance was very low (1-10 reads per million (RPM) or in some cases 11-100 RPM) in sRNA libraries prepared from different Solanaceae species such as petunia, pepper, potato, tomato and tobacco [15]. Furthermore, the remaining six miRNA groups were distributed across species with diverse lineage enrichment and one of them (group 8, containing miR1919, miR4376, miR5300, miR53001, miR6022, miR6023, miR6024, miR6025, miR6026, miR6027 and miR6149) was shown to be predominant in Solanaceae species [15]. As expected, in our libraries we identified several miRNA families that belong to group 8 such as miR1919, miR4376, miR6025 and miR6149. Among the group 8 miRNA families the miR6149 abundance level was the highest in our libraries similar to the tobacco libraries reported by Chavez Montes et al. [15]. Some of the group 8 miRNA families were missing from our libraries (miR5300, miR5301, miR6022, miR6023, miR6024, miR6026 and miR6027), however those miRNA families also showed low abundance $(0-100$ RPM) in the reported tobacco libraries (such as miR5300, miR5301, miR6023 and miR6027) [15].

We also identified several miRNA families which were identified previously as tobacco ( $N$. tabacum) specific miRNAs such as miR6019, miR6020, miR6147, miR6151, miR6153, miR6155, miR6157 and miR6161 [23, 24]. These miRNA families generally showed low abundance across 


\begin{tabular}{|c|c|c|c|c|c|c|c|c|c|c|c|c|c|}
\hline \multicolumn{14}{|c|}{ Conserved and other known miRNAs in Nicotiana benthamiana } \\
\hline \multirow{2}{*}{ miRNA family } & \multirow{2}{*}{ Sequence } & \multicolumn{12}{|c|}{ Normalized number of reads found in Nicotiana benthamiana ${ }^{1}$} \\
\hline & & Seedling (1) & Seedling (2) & Root (1) & Root (2) & Leaf (1) & Leaf (2) & Stem (1) & Stem (2) & Flower (1) & Flower (2) & Leaf $^{\mathrm{BTI}}$ & Seedling ${ }^{\mathrm{BT}}$ \\
\hline \multicolumn{14}{|l|}{ Conserved miRNAs } \\
\hline Nb_miR156 & TGACAGAAGAGAGTGAGCAC & 1349,1 & 1552,4 & 180,8 & 153,5 & 89,8 & 46,8 & 15,4 & 10,7 & 76,9 & 421,4 & 1083,5 & 94,9 \\
\hline Nb_miR159 & TTTGGATTGAAGGGAGCTCTA & 10984,0 & 21181,7 & 2699,2 & 3375,4 & 9249,3 & 16598,4 & 10296,6 & 8866,1 & 3072,5 & 4084,3 & 19421,5 & 18889,4 \\
\hline Nb_miR160 & TGCCTGGCTCCCTGTATGCCA & 40,4 & 71,4 & 8,1 & 64,5 & 49,3 & 82,7 & 21,9 & 25,2 & 52,8 & 0,0 & 84,7 & 142,9 \\
\hline Nb_miR162 & TCGATAAACCTCTGCATCCAG & 97,4 & 113,9 & 77,9 & 207,8 & 57,8 & 49,2 & 129,2 & 120,2 & 121,4 & 197,9 & 87,6 & 43,5 \\
\hline Nb_miR164 & TGGAGAAGCAGGGCACGTGCA & 15,7 & 18,9 & 15,4 & 8,0 & 24,5 & 10,3 & 34,4 & 34,5 & 7,4 & 11,2 & 27,0 & 25,4 \\
\hline Nb_miR165 & TCGGACCAGGCTTCATCCCCC & 6,0 & 2,9 & 11,8 & 2,9 & 3,2 & 2,7 & 3,2 & 1,7 & 2,0 & 1,3 & 0,4 & 1,3 \\
\hline Nb_miR166 & TCGGACCAGGCTTCATTCCCC & 22503,5 & 30402,3 & 49827,5 & 16382,0 & 18238,7 & 35404,3 & 11528,2 & 11504,3 & 7670,7 & 43010,2 & 36612,8 & 41972,3 \\
\hline Nb_miR167 & TGAAGCTGCCAGCATGATCTA & 93,0 & 92,5 & 43,2 & 138,7 & 82,6 & 98,1 & 1,2 & 3,3 & 70,8 & 17,5 & 63,2 & 66,9 \\
\hline Nb_miR168 & TCGCTTGGTGCAGGTCGGGAC & 836,0 & 603,7 & 509,6 & 303,5 & 275,3 & 223,2 & 279,5 & 410,6 & 337,6 & 290,3 & 239,7 & 295,6 \\
\hline Nb_miR169 & TAGCCAAGGATGACTTGCCT & 3,8 & 3,7 & 9,3 & 2,7 & 6,7 & 3,8 & 2,8 & 22,9 & 0,5 & 16,3 & 2,5 & 14,8 \\
\hline Nb_miR171 & TTGAGCCGCGCCAATATCACT & 20,7 & 31,6 & 10,7 & 20,8 & 13,6 & 10,9 & 10,1 & 16,6 & 15,4 & 25,6 & 23,6 & 24,3 \\
\hline Nb_miR172 & AGAATCTTGATGATGCTGCAT & 0,9 & 1,2 & 0,0 & 9,1 & 10,4 & 9,6 & 16,6 & 20,3 & 7,4 & 3,2 & 2,1 & 11,7 \\
\hline Nb_miR319 & TTGGACTGAAGGGAGCTCCCT & 234,6 & 398,0 & 372,5 & 1772,2 & 68,2 & 54,3 & 2212,8 & 3650,6 & 1342,0 & 834,6 & 278,5 & 41,8 \\
\hline Nb_miR390 & AAGCTCAGGAGGGATAGCGCC & 37,9 & 50,1 & 30,0 & 34,7 & 13,6 & 8,5 & 13,4 & 16,7 & 18,2 & 68,2 & 14,3 & 22,4 \\
\hline Nb_miR393 & TCCAAAGGGATCGCATTGATCC & 9,1 & 25,4 & 5,0 & 15,4 & 17,9 & 21,9 & 12,6 & 10,8 & 9,1 & 18,4 & 24,9 & 30,8 \\
\hline Nb_miR394 & TTGGCATTCTGTCCACCTCC & 12,8 & 23,9 & 1,1 & 34,4 & 25,0 & 13,7 & 25,9 & 20,9 & 19,1 & 0,0 & 15,2 & 40,6 \\
\hline Nb_miR395 & CTGAAGTGTTTGGGGGAACTC & 1,6 & 2,3 & 2,5 & 0,7 & 0,3 & 0,0 & 0,4 & 0,0 & 1,1 & 0,0 & 2,5 & 0,1 \\
\hline Nb_miR396 & TTCCACAGCTTTCTTGAACTG & 1284,9 & 1663,6 & 3241,4 & 978,8 & 2348,4 & 580,7 & 1222,7 & 1179,9 & 738,6 & 4853,8 & 800,8 & 394,5 \\
\hline Nb_miR397 & TCATTGAGTGCAGCGTTGATG & 35,4 & 33,3 & 15,1 & 14,8 & 46,6 & 43,4 & 5,3 & 7,5 & 11,8 & 6,6 & 4,6 & 27,9 \\
\hline Nb_miR398 & TATGTTCTCAGGTCGCCCCTG & 244,3 & 89,6 & 323,8 & 324,7 & 222,5 & 173,3 & 19,0 & 19,8 & 201,3 & 28,7 & 24,0 & 81,8 \\
\hline Nb_miR399 & TGCCAAAGGAGAGTTGCCCTG & 0,9 & 1,0 & 0,3 & 2,6 & 2,1 & 1,7 & 1,6 & 3,9 & 1,9 & 0,0 & 0,0 & 0,6 \\
\hline Nb_miR403 & TTAGATTCACGCACAAACTCG & 1360,0 & 3018,8 & 683,1 & 628,3 & 832,2 & 2390,7 & 666,0 & 716,0 & 428,2 & 1694,8 & 3756,8 & 3676,3 \\
\hline Nb_miR408 & TGCACTGCCTCTTCCCTGGCT & 44,5 & 44,7 & 35,0 & 67,2 & 99,1 & 180,1 & 16,2 & 17,4 & 32,4 & 9,6 & 23,2 & 124,2 \\
\hline \multicolumn{14}{|c|}{ Other known miRNAs } \\
\hline Nb_miR170 & TATTGGCCTGGTTCACTCAGA & 20,7 & 31,6 & 0,0 & 20,8 & 13,6 & 10,9 & 6,5 & 10,7 & 15,4 & 0,0 & 23,6 & 21,7 \\
\hline Nb_miR477 & ССТСTСССTCAAGGGCTTCTC & 0,3 & 1,0 & 7,3 & 0,7 & 0,3 & 0,3 & 3,2 & 4,6 & 0,2 & 11,9 & 0,0 & 1,0 \\
\hline Nb_miR479 & CGTGATATTGGTTTGGCTCATC & 11,9 & 10,4 & 56,3 & 94,1 & 2,9 & 2,1 & 113,4 & 151,2 & 68,8 & 36,2 & 15,2 & 3,8 \\
\hline Nb_miR482 & TTTCCAATTCCACCCATTCCTA & 1044,9 & 1750,4 & 102,9 & 140,0 & 1334,8 & 3879,8 & 699,6 & 675,1 & 153,6 & 128,6 & 2854,1 & 3958,0 \\
\hline Nb_miR827 & TTAGATGAACATCAACAAACA & 3,8 & 7,2 & 0,0 & 0,9 & 10,1 & 13,0 & 0,8 & 0,5 & 0,9 & 0,0 & 7,2 & 17,6 \\
\hline Nb_miR1446 & TGAACTCTCTCCСTCAATGGCT & 0,6 & 2,3 & 5,9 & 5,1 & 1,3 & 0,7 & 0,0 & 0,2 & 4,5 & 4,7 & 0,4 & 2,6 \\
\hline Nb_miR1919 & TGTCGCAGATGACTTTCGCCC & 23,2 & 70,8 & 0,8 & 4,9 & 6,1 & 32,5 & 28,8 & 5,8 & 2,3 & 1,6 & 269,6 & 38,7 \\
\hline Nb_miR4376 & TACGCAGGAGAGATGATGCTG & 2,2 & 1,3 & 2,5 & 1,5 & 25,6 & 21,2 & 2,8 & 20,5 & 2,7 & 0,4 & 2,5 & 7,5 \\
\hline Nb_miR6019 & TACAGGTGACTTGTAAATGTTT & 5,6 & 8,8 & 5,6 & 6,4 & 12,5 & 16,4 & 11,7 & 10,3 & 5,9 & 1,5 & 12,6 & 11,7 \\
\hline Nb_miR6020 & АAATGTTCTTCGAGTATCTTC & 4,4 & 13,5 & 4,5 & 4,2 & 28,2 & 34,5 & 16,6 & 19,1 & 2,3 & 2,1 & 9,3 & 42,9 \\
\hline Nb_miR6025 & TACCAACAATTGAGATAACATC & 17,2 & 19,9 & 7,0 & 17,7 & 26,9 & 24,6 & 24,7 & 17,0 & 13,6 & 8,3 & 42,1 & 33,9 \\
\hline Nb_miR6147 & TGACATCTTCAAAACCCACTA & 13,8 & 26,6 & 5,6 & 7,3 & 22,7 & 12,6 & 4,1 & 10,8 & 4,9 & 5,9 & 26,1 & 22,4 \\
\hline Nb_miR6149 & TTGATACGCACCTGAATCGGC & 3043,6 & 9858,0 & 391,0 & 345,9 & 5241,0 & 14675,9 & 2261,0 & 1957,7 & 354,5 & 1180,0 & 11671,5 & 23801,7 \\
\hline Nb_miR6151 & TGAGTGTGAGGCGTTGGATTGA & 3,4 & 4,3 & 7,3 & 2,2 & 5,9 & 4,8 & 2,8 & 3,0 & 1,1 & 8,5 & 2,9 & 3,1 \\
\hline Nb_miR6153 & TAGGACCATATTCACTATTTG & 338,3 & 328,1 & 214,7 & 218,0 & 374,1 & 273,8 & 188,8 & 251,8 & 160,7 & 451,3 & 210,6 & 309,7 \\
\hline Nb_miR6155 & TAAGGTTGCCTTGCTCTTGCA & 134,1 & 300,7 & 8,4 & 23,9 & 175,9 & 336,6 & 42,5 & 29,3 & 21,7 & 0,1 & 525,3 & 373,8 \\
\hline Nb_miR6157 & TGGTAGACGTAGGATTTGAA & 6,6 & 10,2 & 31,4 & 11,5 & 2,1 & 2,7 & 13,4 & 14,3 & 4,3 & 41,3 & 10,1 & 1,8 \\
\hline Nb_miR6161 & GCTGGACCGGTATACTTTGC & 1,6 & 2,1 & 1,7 & 1,5 & 0,8 & 1,4 & 4,1 & 2,1 & 1,5 & 2,6 & 5,5 & 2,9 \\
\hline \multicolumn{5}{|c|}{$x<1$} & \multicolumn{2}{|c|}{$1<x<100$} & 100 & $<500$ & \multicolumn{2}{|c|}{$500<X<1000$} & \multicolumn{2}{|c|}{$x>1000$} & \\
\hline
\end{tabular}

Fig. 2 Conserved and other known miRNAs in N. benthamiana. Normalized read numbers of conserved and other known miRNAs across the tissues included in this study. Expression profiles are expressed in reads per million (RPM) genome matching reads. Heat map colours represents absolute normalized levels of miRNA expression ranging from less than 1 RPM (white) to more than 1000 RPM (red) as indicated in the colour key. We have identified 40 known or conserved miRNA families in the twelve sRNA libraries generated. All of the deeply conserved miRNA families (miR156/157, miR159/319, miR160, miR165/166, miR171, miR408, miR390/391 and miR395) were present in our data sets. The expression levels of different miRNA families were different and we also observed clear tissue-specific expressional changes within some miRNA families as it was expected

all tissues in our libraries with the exception of miR6153, which was expressed at medium levels in all samples (160-450 RPM across all tissue) and miR6155, which was relatively abundant in leaf and seedling samples (175-525 RPM) (Fig. 2).

We checked the size distribution and starting nucleotide of the conserved and known miRNA families in our libraries. In 30 miRNA families, 21 nt long miRNAs were the most significant size class (Fig. 3a). In several cases they were accompanied by additional size classes, mostly $20 \mathrm{nu}-$ cleotide long sequences or in some cases 22 nucleotide sequences were present in significant proportions (miR4376, miR393, miR167 and miR6157). Three miRNA families exhibited a strong preference for 20 nucleotide sequences and in seven miRNA families the 22 nucleotide long sequences were the most abundant size class (Fig. 3a). Our observation that the miR394 has a predominant 20 nucleotide size in our libraries is consistent with previous result and it might suggest a functional consequence since its size and sequence is conserved in terrestrial plant species [15]. It was shown in several cases that size specificity has a functional consequence, like the 22 nucleotide preference of phase initiating miRNAs associated with the generation of tasiRNAs $[25,26]$. We found seven miRNA families with the 22 nucleotide sequence dominance and two of them (miR6019 and miR482) belongs to the described phase initiating miRNAs [23, 27, 28]. It is likely they are also involved in tasiRNA generation in $N$. benthamiana. 


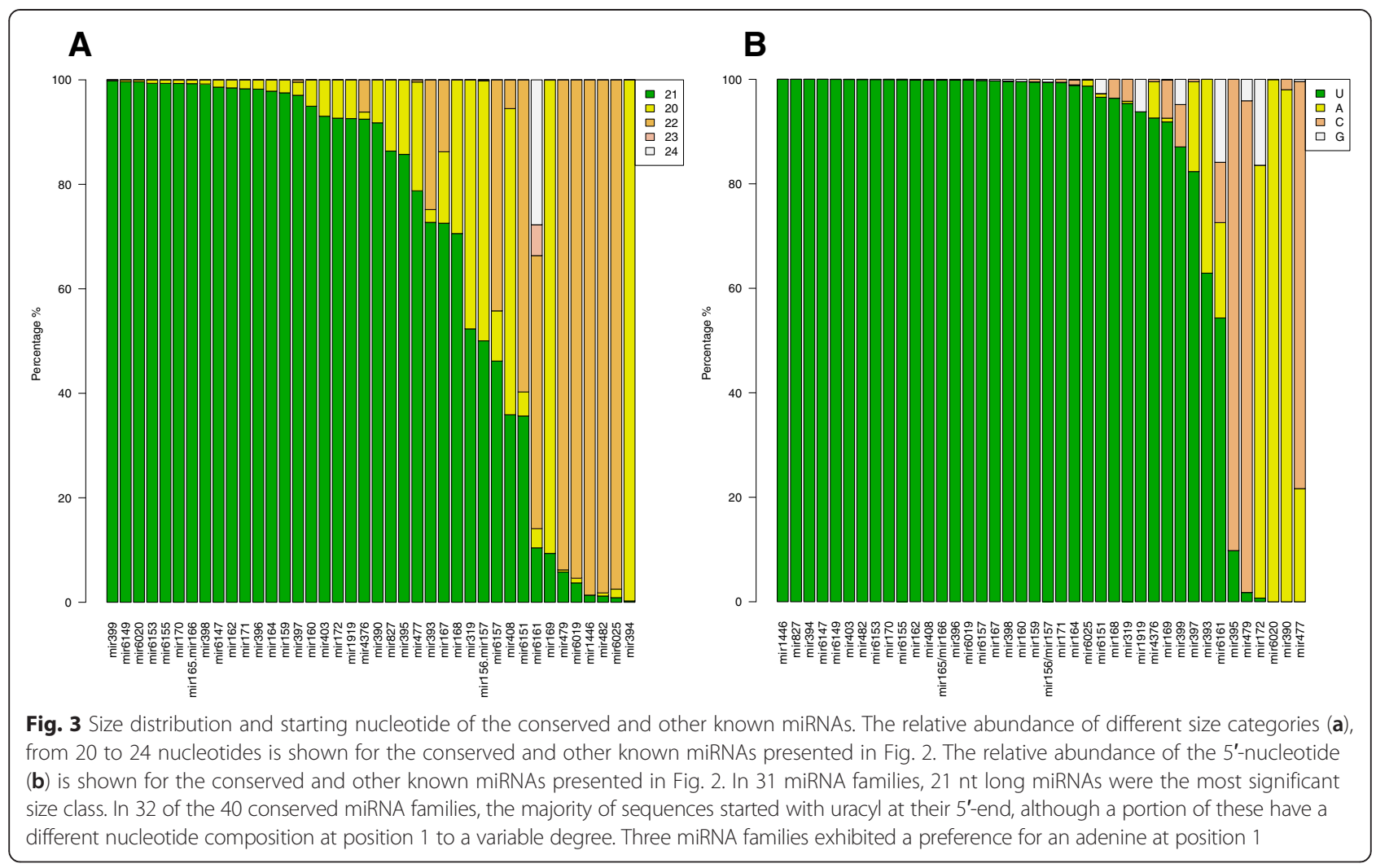

Sorting of sRNAs into AGO complexes is influenced by their $5^{\prime}$ terminal nucleotide. Hence, we checked the $5^{\prime}$-nucleotide distribution of the conserved and known miRNA families in our libraries, since it is an important feature that is correlating to their biogenesis and function [29]. In 34 of the 40 conserved miRNA families, the majority of sequences started with uracyl at their 5 '-end, although a portion of these have a different nucleotide composition at position 1 to a variable degree (Fig. 3b). Three miRNA families exhibited a preference for an adenine at position 1, although one of them has a different nucleotide composition at position 1 to a variable degree (miR172). In three miRNA families the most frequently found first nucleotide at their $5^{\prime}$-end was cytosine (miR395, miR479, miR477). miRNAs mostly are incorporated into the AGO1 effector complex to give sequence specificity to either slice or translationally repress their target mRNAs [12]. AGO1 harbours miRNAs that favour a $5^{\prime}$ terminal uridine [30]. In line with this observation, most of the conserved and known miRNA families in our libraries started with uracyl at their 5 '-end. We also found several miRNAs that start with either adenine or cytosine (miR172, miR390 and miR395). It was reported in many different plant species that miRNAs belonging to these miRNA families are starting with the same nucleotide at the $5^{\prime}$-position [15].
Many plant miRNAs show tissue-specific and developmental-stage-specific expression patterns and they have important roles during development and stress adaptation [13]. To validate the tissue-specific expression patterns of selected conserved and known miRNAs we carried out Northern blot analysis using seedling $(\mathrm{Se})$, root $(\mathrm{R})$, leaf $(\mathrm{L})$, stem $(\mathrm{St})$ and flower $(\mathrm{F})$ samples isolated from our $N$. benthamiana line; and leaf $\left(\mathrm{L}^{\mathrm{BTI}}\right)$ and seedling $\left(\mathrm{Se}^{\mathrm{BTI}}\right)$ samples from $N$. benthamiana $\mathrm{Nb}-1$ accession that were obtained from the Boyce Thompson Institute for Plant Research. Northern analysis usually was in broad agreement with the sequencing data as in the cases of miR156, miR159, miR162, miR164, miR165, miR168, miR390 and miR393 (Fig. 4). In certain cases we observed a discrepancy between the Northern blot and sequencing data, as in the cases of miR167, miR171, miR482, miR6025 and miR6149 (Fig. 4; Fig. 2). However, these differences are not unexpected as it has been reported that Northern analysis are not always in full agreement with the sequencing data, presumably due to the inherent biases in next-generation sequencing technologies [31-36]. Theoretically, the oligoprobes used for Northern analysis might have detected heterogeneous miRNAs. However, we expect that Northern analysis should reveal more accurate in vivo expression patterns. We also performed RT-qPCR analysis to validate our 


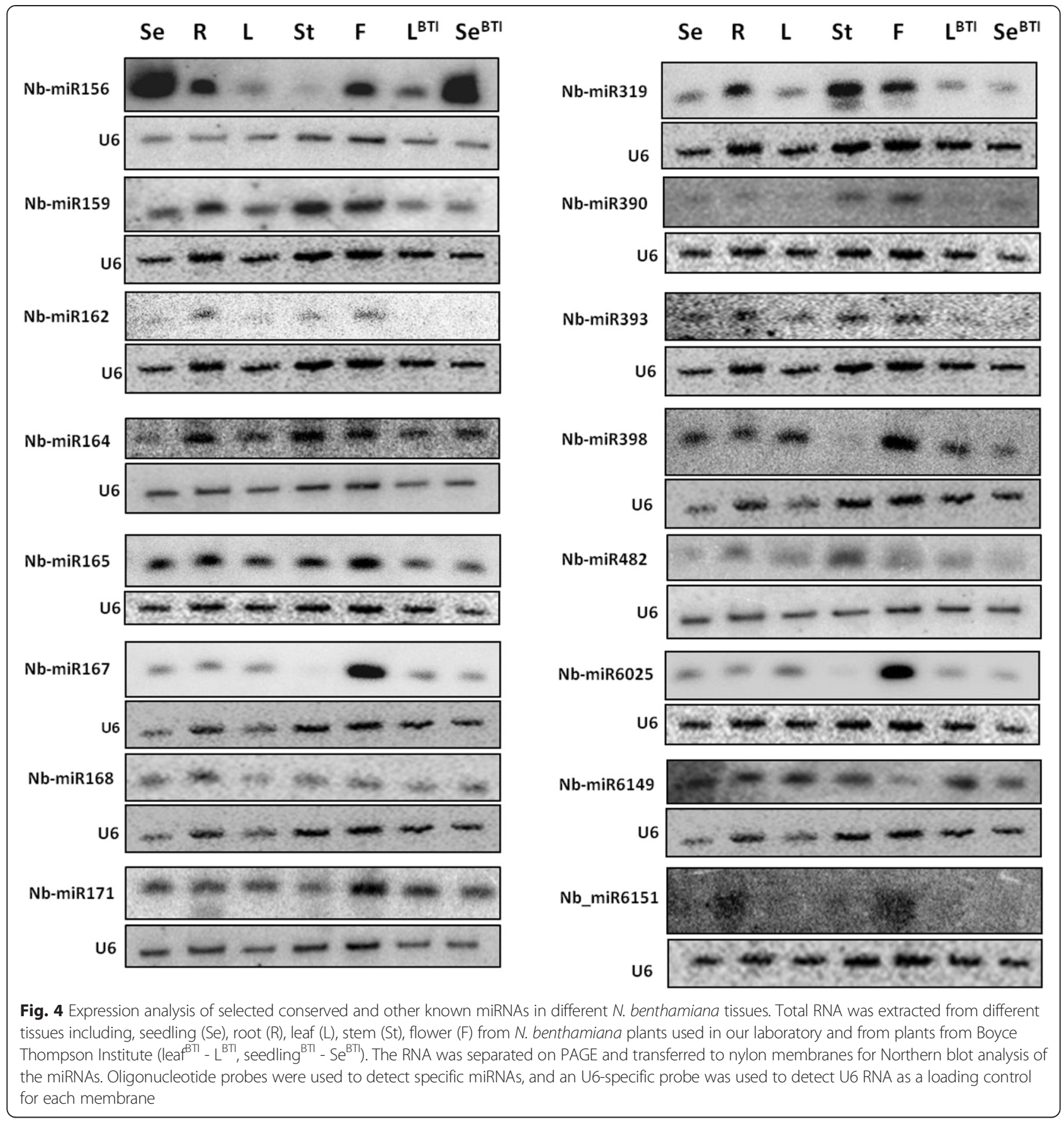

Northern results by checking the expression pattern of miR167 and miR482 in N. benthamiana tissues. We found that the results of Northern analysis and RTqPCR were identical (Additional file 2 Figure S1.). Furthermore, comparing the Northern analysis data of our $N$. benthamiana line to the $\mathrm{Nb}-1$ accession to detect tissue specific expression pattern of miRNAs, we were not able to confirm the differences occasionally observed in the miRNA read numbers at certain miRNA families (in seedlings: miR156, miR168, miR319, miR396,
miR482 and miR6149; in leaf: miR156, miR319, miR398, miR403 and miR1919) (Fig. 4). Our miRNA expression data therefore might indicate that these $N$. benthamiana lines are closely related based on their very similar miRNA expression patterns.

\section{Targets of conserved and known miRNAs}

To generate a miRNA cleaved target library (degradome) from $N$. benthamiana we applied a high-throughput experimental approach that can identify mRNAs targeted 
by sRNAs [37]. The poly-A fraction of total RNA extracted from seedling (Se), root $(\mathrm{R})$, leaf $(\mathrm{L})$, stem $(\mathrm{St})$, flower (F) of $N$. benthamiana plants; and leaf $\left(\mathrm{L}^{\mathrm{BTI}}\right)$ and seedling $\left(\mathrm{Se}^{\mathrm{BTI}}\right)$ of the $\mathrm{Nb}-1$ accession were analysed for the identification of target transcripts of conserved, other known, and new miRNAs.

We obtained a total number of 47 million short sequencing reads representing the $5^{\prime}$ ends of uncapped, poly-adenylated RNAs. After initial processing, equal numbers of 20- and 21-nt sequence reads were obtained, and $48 \%$ of the short sequencing reads could be mapped to the $N$. bentamiana transcriptome.

In plants, miRNA mediated mRNA cleavage is highly specific and miRNAs have been shown to bind with near perfect complementarity to their mRNA targets, which generally leads to the slicing of the mRNA between positions 10 and 11 of the AGO1 bound miRNA. As a consequence, the cleaved mRNA targets should have distinct peaks in the degradome sequence tags at the predicted cleavage site relative to the other regions of the transcript $[38,39]$. In our analysis we have applied the PAREsnip pipeline [40] to identify cleaved targets for both known (conserved and non-conserved) and new miRNAs in $N$. benthamiana. Abundance of the sequenced tags was plotted on each transcript and the results are shown on Additional file 3: Figure S2. The cleaved target transcripts have been categorized into five classes (categories 0, 1, 2, 3 and 4) as it was defined previously in CleaveLand (version2) [41]. In our target list we kept high-confidence miRNAtarget gene interactions (categories 0, 1, 2) and only category 3 targets as low-confidence miRNA-target pairs. Category 4 targets are defined as only one raw read at the expected cleavage position, however it might also be the result of the degradation of the target RNA, therefore they were omitted from our target list. This approach identified a total of 55 target mRNAs, for conserved and other known miRNAs (Table 2, Additional file 4: Table S2).

Altogether we found 44 targets for conserved miRNAs, from which 23 were classed as category 0 , six as category 1 and fifteen as category 2. For other known miRNAs we have found 11 targets, from which one was classed as category 0 , two as category 1 and eight as category 2 .

We identified targets for 18 conserved miRNA families out of 23. Some of the conserved miRNAs without any identified targets (miR390 and miR399) were expressed at a low level in all of the sRNA libraries (Fig. 2), which may explain the lack of detection of cleaved targets. However, both miR162 and miR403 were expressed at a considerable level in at least some of the tissues (Fig. 2) without mRNA targets identified in the degradome libraries. As an alternative explanation these miRNAs might be engaged in translational repression, however in different plant species cleaved target mRNAs were identified as their target which makes this explanation less plausible [13]. We have confirmed 29 conserved targets of conserved miRNAs already identified in different plants [13]. Many of the identified conserved targets are members of different families of transcription factors, such as squamosal promoter-binding (SBP), MYB, ARF, NAC, HD-ZIPIII, CCAAT-binding, AP2 and TCP. In addition to these targets we also identified 15 new targets in $N$. benthamiana for conserved miRNAs (Table 2). We found one target of the non-conserved miR4376 which was already identified in tomato [42]. We also identified nine new targets of seven non-conserved miRNAs (Table 2). Most of the non-conserved miRNA families for which no target had been identified were expressed at a very low level in all tissues (miR170, miR477, miR1446, miR6019, miR6025, miR6147), except miR479, miR1919, miR6153 and miR6155 (expressed at moderate level at least in one sample) (Table 2, Fig. 2).

\section{$N$. benthamiana specific miRNAs}

We used strict criteria to identify new miRNAs. Briefly, the sRNA reads were mapped to the $N$. benthamiana genome and secondary structures were predicted for each locus. Based on the hairpin prediction, the presence of miRNA* strands in the sRNA libraries and validated target mRNA in the degradome libraries we found 18 new miRNA candidates (Fig. 5, Additional file 5: Figure S3.). $\mathrm{Nb} \_$miRC1_3p was the most abundant Nicotiana specific miRNA in our sRNA libraries and it expressed in all of the tissues. The sequence of Nb_miRC1_3p was also reported previously from a large scale sRNA dataset as endogenous small RNA of Nicotiana attenuata [43], however it was not further investigated which small RNA class it belongs to. The second most abundant miRNA was the Nb_miRC2_3p and it was also present in all of the small RNA libraries. For the remaining $N$. benthamiana specific miRNAs the relative number of reads in all tissues was low (Fig. 5). However, this result is in line with the observation shown previously, that miRNA abundance decreases as the conservation of the sequence decreases [15].

As a next step, we checked the size distribution and starting nucleotide of the new $N$. benthamiana specific miRNAs in our libraries. The $21 \mathrm{nt}$ long miRNAs were the most significant size class and half of the new miRNAs belong to this group (Fig. 6a). In several cases they were accompanied by additional size class, 20 nucleotide long sequences were present in significant proportions (Nb_miRC18_3p and Nb_miRC11_5p). Three miRNAs exhibited a strong preference for 22 nucleotide sequences (Nb_miRC6_3p, Nb_miRC4_3p and Nb_miRC14_5p) and in five miRNA families the 24 nucleotide long sequences were the most abundant size class (Nb_miRC8_3pa, Nb_miRC17_5p, Nb_miRC7_3p, Nb_miRC13_3p and Nb_miRC10_3p). We found that two miRNA families showed the coexistence of 20-24 nucleotide variants with 
Table 2 Targets of conserved and other known miRNAs in Nicotiana benthamiana ${ }^{a}$

\begin{tabular}{|c|c|c|c|c|c|c|}
\hline miRNA family & miRNA sequence & Gene ID & $\begin{array}{l}\text { Clevage } \\
\text { position }\end{array}$ & Category & $\begin{array}{l}\text { Normalized } \\
\text { abundance }^{a}\end{array}$ & Annotation \\
\hline \multicolumn{7}{|c|}{$\begin{array}{l}\text { Conserved miRNAs } \\
\text { and their targets }\end{array}$} \\
\hline Nb_miR156 & TGACAGAAGAGAGTGAGCAC & $\begin{array}{l}\text { comp77119_c0_seq6 } \\
\text { 2667_2942 }\end{array}$ & 1787 & 0 & 2,40 & $\begin{array}{l}\text { Squamosa promoter-binding-like } \\
\text { protein } 6\end{array}$ \\
\hline Nb_miR156 & TGACAGAAGAGAGTGAGCAC & comp69399_c0_seq4 393_944 & 650 & 2 & 1,28 & $\begin{array}{l}\text { Squamosa promoter-binding-like } \\
\text { protein } 16\end{array}$ \\
\hline Nb_miR159 & TTTGGATTGAAGGGAGCTCTA & comp71582_c0_seq2 1_1230 & 673 & 0 & 40,63 & No annotation ${ }^{b}$ \\
\hline Nb_miR159 & TTTGGATTGAAGGGAGCTCTA & comp69815_c0_seq4 1_894 & 601 & 0 & 0,39 & Transcription factor GAMYB \\
\hline Nb_miR159 & TTTGGATTGAAGGGAGCTCTA & comp73942_c0_seq1 927_2375 & 1839 & 0 & 2,14 & Transcription factor GAMYB \\
\hline Nb_miR160 & TGCCTGGCTCCCTGTATGCCA & comp78286_c0_seq3 693_2783 & 2065 & 0 & 307,20 & Auxin response factor 18 \\
\hline Nb_miR160 & TGCCTGGCTCCCTGTATGCCA & $\begin{array}{l}\text { comp79462_c0_seq1 } \\
\text { 2477_3379 }\end{array}$ & 2658 & 0 & 6,41 & Auxin response factor 16 \\
\hline Nb_miR164 & TGGAGAAGCAGGGCACGTGCA & comp72325_c0_seq2 310_1305 & 994 & 0 & 3,43 & Protein CUP-SHAPED COTYLEDON 2 \\
\hline Nb_miR165/166 & TCGGACCAGGCTTCATTCCCC & $\begin{array}{l}\text { comp80060_c0_seq5 } \\
\text { 1298_3817 }\end{array}$ & 1868 & 0 & 51,20 & $\begin{array}{l}\text { Homeobox-leucine zipper protein } \\
\text { REVOLUTA }\end{array}$ \\
\hline Nb_miR165/166 & TCGGACCAGGCTTCATTCCTC & $\begin{array}{l}\text { comp79517_c0_seq6 } \\
\text { 1043_3556 }\end{array}$ & 1601 & 0 & 246,61 & $\begin{array}{l}\text { Homeobox-leucine zipper protein } \\
\text { ATHB-15 }\end{array}$ \\
\hline Nb_miR165/166 & TCGGACCAGGCTTCATTCCTC & comp79347_c3_seq8 336_611 & 546 & 1 & 1,60 & No annotation ${ }^{\mathrm{b}}$ \\
\hline Nb_miR167 & AGATCATGTGGTAGCTTCACC & comp79742_c0_seq4 124_2421 & 1700 & 2 & 5,90 & $\begin{array}{l}\text { 5-methyltetrahydropteroyltriglutamate- } \\
\text {-homocysteine methyltransferase }\end{array}$ \\
\hline Nb_miR167 & AGATCATGTGGTAGCTTCACC & comp74516_c0_seq2 292_2619 & 1160 & 2 & 3,54 & Subtilisin-like protease ${ }^{b}$ \\
\hline Nb_miR168 & TCGCTTGGTGCAGGTCGGGACC & comp79927_c1_seq7 1_243 & 876 & & 1,60 & Protein argonaute $1 \mathrm{~A}$ \\
\hline Nb_miR169 & TAGCCAAGGATGACTTGCCT & $\begin{array}{l}\text { comp72459_c1_seq2 } \\
\text { 1230_1673 }\end{array}$ & 1724 & 2 & 0,19 & $\begin{array}{l}\text { Nuclear transcription factor } Y \text { subunit } \\
\text { A-5/CCAAT-binding transcription factor }\end{array}$ \\
\hline Nb_miR169 & TAGCCAAGGATGACTTGCCT & $\begin{array}{l}\text { comp72338_c0_seq4 } \\
\text { 1046_1396 }\end{array}$ & 1439 & 2 & 0,29 & $\begin{array}{l}\text { Nuclear transcription factor } Y \text { subunit } \\
\text { A-5/CCAAT-binding transcription factor }\end{array}$ \\
\hline Nb_miR169 & TAGCCAAGGATGACTTGCCT & $\begin{array}{l}\text { comp73705_c1_seq8 } \\
\text { 1254_1739 }\end{array}$ & 1836 & 1 & 3,15 & $\begin{array}{l}\text { Nuclear transcription factor } Y \text { subunit } \\
\text { A-8/CCAAT-binding transcription factor }\end{array}$ \\
\hline Nb_miR169 & TAGCCAAGGATGACTTGCCT & comp67524_c0_seq9 544_1167 & 1246 & 0 & 1,96 & $\begin{array}{l}\text { Nuclear transcription factor } Y \text { subunit } \\
\text { A-10/CCAAT-binding transcription factor }\end{array}$ \\
\hline Nb_miR171 & TTGAGCCGCGCCAATATCACG & comp76988_c0_seq2 277_1911 & 896 & 0 & 26,05 & Scarecrow-like protein 15 \\
\hline Nb_miR171 & TTGAGTCGCGCCAATATCACT & comp80119_c0_seq4 672_2573 & 1552 & 0 & 34,34 & Scarecrow-like protein 6 \\
\hline Nb_miR171 & TTGAGTCGCGCCAATATCACT & comp75200_c0_seq2 459_2717 & 1696 & 0 & 109,89 & Scarecrow-like protein 6 \\
\hline Nb_miR172 & AGAATCTTGATGATGCTGCAG & comp78340_c2_seq4 552_1409 & 2200 & 0 & 4,42 & $\begin{array}{l}\text { Floral homeotic protein } \\
\text { APETALA } 2\end{array}$ \\
\hline Nb_miR319 & TTGGACTGAAGGGAGCTCCCT & comp68096_c0_seq1 79_1191 & 1046 & 0 & 1,02 & Transcription factor TCP4 \\
\hline
\end{tabular}


Table 2 Targets of conserved and other known miRNAs in Nicotiana benthamiana ${ }^{\text {a }}$ (Continued)

\begin{tabular}{|c|c|c|c|c|c|c|}
\hline Nb_miR319 & TTGGACTGAAGGGAGCTCCCT & $\begin{array}{l}\text { comp73714_c2_seq12 } \\
\text { 2093_2317 }\end{array}$ & 2006 & & 0,98 & Transcription factor TCP2 \\
\hline Nb_miR393 & TCCAAAGGGATCGCATTGATCC & comp80206_c0_seq2 468_4724 & 4235 & 2 & 0,29 & No annotation ${ }^{b}$ \\
\hline Nb_miR394 & TTGGCATTCTGTCCACCTCC & $\begin{array}{l}\text { comp60101_c0_seq1 } \\
\text { 5351_5605 }\end{array}$ & 5291 & 2 & 2,16 & Tripeptidyl-peptidase $2^{\mathrm{b}}$ \\
\hline Nb_miR395 & CTGAAGTGTTTGGGGGAACTC & comp75863_c0_seq1 200_1609 & 553 & 2 & 0,53 & ATP sulfurylase 1, chloroplastic \\
\hline Nb_miR395 & CTGAAGTGTTGGGGGAACTC & comp29318_c1_seq1 108_620 & 254 & 0 & 1,07 & Sulfate transporter 2.1 \\
\hline Nb_miR396 & TTCCACATCTTTCTTGAACTG & $\begin{array}{l}\text { comp71133_c0_seq1 } \\
\text { 1089_1355 }\end{array}$ & 935 & 2 & 2,10 & $\begin{array}{l}\text { Protein THYLAKOID FORMATION1 } \\
\text {, chloroplastic }\end{array}$ \\
\hline Nb_miR396 & TTCCACAGCTTTCTTGAACTG & comp77639_c0_seq4 942_2765 & 1723 & 0 & 4,42 & Growth-regulating factor 6 \\
\hline Nb_miR396 & TTCCACAGCTTTCTTGAACTG & comp67678_c0_seq1 205_573 & 279 & 0 & 12,19 & Thioredoxin $\mathrm{H}$-type $1^{\mathrm{b}}$ \\
\hline Nb_miR396 & TTCCACAGCTTTCTTGAACTG & comp50987_c1_seq1 2_379 & 144 & 1 & 0,48 & $40 \mathrm{~S}$ ribosomal protein $\mathrm{S} 15^{\mathrm{b}}$ \\
\hline Nb_miR396 & TTACACAGCTTTCTTGAACTG & comp69468_c0_seq1 204_1724 & 1425 & 2 & 0,58 & Protein IQ-DOMAIN $14^{\mathrm{b}}$ \\
\hline Nb_miR396 & TTCCACAGCTTTCTTGAACTG & comp77795_c0_seq2 2_1780 & 1546 & & 0,58 & $\begin{array}{l}\text { Pentatricopeptide repeat-containing } \\
\text { protein At5g04810, chloroplastic }{ }^{b}\end{array}$ \\
\hline Nb_miR396c & TTCCACAGCTTTCTTGAACTG & $\begin{array}{l}\text { comp77334_c1_seq28 } \\
\text { 1342_2196 }\end{array}$ & 1370 & 0 & 3,74 & Growth-regulating factor 5 \\
\hline Nb_miR396 & TTCCACAGCTTTCTTAAACTG & comp79406_c0_seq1 393_3506 & 1932 & 2 & 0,29 & No annotation ${ }^{\mathrm{b}}$ \\
\hline Nb_miR396 & TTCCACAGCTTTCTTGAACTG & comp76253_c0_seq1 643_1557 & 767 & 0 & 0,19 & Growth-regulating factor 9 \\
\hline Nb_miR396 & TTCCACAGCTTTCTTGGACTG & comp69128_c0_seq2 114_806 & 521 & 2 & 0,19 & $\begin{array}{l}\text { DNA-directed RNA polymerase } \\
V \text { subunit } 5 A-I \text { ike }\end{array}$ \\
\hline Nb_miR397 & TCATTGAGTGCAGCGTTGATG & comp73318_c2_seq1 87_1109 & 883 & 2 & 4,42 & $\begin{array}{l}\text { Glyceraldehyde-3-phosphate } \\
\text { dehydrogenase, cytosolic }\end{array}$ \\
\hline Nb_miR397 & TCATTGAGTGCAGCGTTGATG & comp75344_c1_seq2 127_1839 & 810 & 2 & 0,24 & Laccase-7 \\
\hline Nb_miR397 & TCATTGAGTGCAGCGTTGATG & $\begin{array}{l}\text { comp77652_c0_seq1 } \\
1261 \_3177\end{array}$ & 176 & 2 & 0,29 & $\begin{array}{l}\text { Probable serine/threonine-protein } \\
\text { kinase } a b k C^{b}\end{array}$ \\
\hline Nb_miR398 & TATGTTCTCAGGTCGCCCCTG & comp100607_c0_seq1 102_557 & 78 & 0 & 9,46 & Umecyanin \\
\hline Nb_miR408 & TGCACTGCCTCTTCCCTGGCT & comp85708_c0_seq1 121_624 & 630 & 0 & 15,30 & Uclacyanin-2 \\
\hline Nb_miR408 & TGCACTGCCTCTTCCCTGGCT & comp79061_c1_seq3 184_1473 & 2346 & 0 & 12,38 & $\begin{array}{l}\text { Copper-transporting ATPase PAA2, } \\
\text { chloroplastic }\end{array}$ \\
\hline \multicolumn{7}{|c|}{$\begin{array}{l}\text { Other known miRNAs and their } \\
\text { targets }\end{array}$} \\
\hline Nb_miR482 & TTCСAАTTCCACCCATTCCTA & comp75828_c0_seq3 249_1742 & 1609 & 2 & 1,07 & No annotation ${ }^{b}$ \\
\hline Nb_miR827 & TTAGATGAACATCAACAAACT & comp75426_c0_seq1 2_226 & 1982 & 2 & 1,36 & UPF0496 protein 4 \\
\hline Nb_miR4376 & TACGCAGGAGAGATGATACTG & comp79500_c0_seq4 305_3562 & 284 & 2 & 0,98 & $\begin{array}{l}\text { Calcium-transporting ATPase } 8 \text {, } \\
\text { plasma membrane-type }\end{array}$ \\
\hline Nb_miR6020 & AAATGTTCTTCGAGTATCTTC & comp70698_c0_seq1 752_1555 & 996 & 1 & 0,68 & GPN-loop GTPase 3 homolog ${ }^{b}$ \\
\hline
\end{tabular}


Table 2 Targets of conserved and other known miRNAs in Nicotiana benthamiana ${ }^{\text {a }}$ (Continued)

\begin{tabular}{|c|c|c|c|c|c|c|}
\hline Nb_miR6020 & AAATGTTCTTCGAGTATCTTC & comp74553_c0_seq5 265_702 & 596 & 0 & 1,47 & No annotation ${ }^{b}$ \\
\hline Nb_miR6020 & AAATGTTCTTCGAGTATCTTC & comp75715_c0_seq5 271_2055 & 1544 & 2 & 0,27 & $\begin{array}{l}\text { Probable methylenetetrahydrofolate } \\
\text { reductase }^{b}\end{array}$ \\
\hline Nb_miR6149 & TTGATACGCACCTGAATCGGG & comp80883_c0_seq1 2_310 & 14 & 2 & 0,27 & Tubulin alpha chain ${ }^{b}$ \\
\hline Nb_miR6149 & TTGATACGCACCTGAATCGGG & comp75221_c0_seq2 455_1678 & 1646 & 2 & 1,77 & Serine/threonine-protein kinase $\mathrm{HT} 1^{\mathrm{b}}$ \\
\hline Nb_miR6151 & TGAGTGTGAGGCGTTGGATTGA & comp84169_c0_seq1 105_1127 & 334 & 2 & 2,10 & Probable carboxylesterase $8^{\mathrm{b}}$ \\
\hline Nb_miR6157 & TGGTAGACGTAGGATTTGAAA & comp66224_c0_seq2 136_780 & 259 & & 0,68 & Ras-related protein RABA2 $b^{b}$ \\
\hline $\mathrm{Nb}$ miR6161 & TGCTGGACCGACATACTITGT & comp74264_c0_seq1 147_1052 & 343 & 2 & 0,48 & $60 S$ ribosomal protein $L 5^{\mathrm{b}}$ \\
\hline
\end{tabular}

${ }^{a}$ The abundance for the degradome fragment (tag) indicating cleavage at that position/total number of fragments $\times 1,000,000$

${ }^{\mathrm{b}} \mathrm{New}$ target in N. benthamiana for conserved and other known miRNAs 


\begin{tabular}{|c|c|c|c|c|c|c|c|c|c|c|c|c|c|c|c|c|c|c|}
\hline \multicolumn{19}{|c|}{ New miRNAs in Nicotiana benthamiana } \\
\hline \multirow[b]{2}{*}{ new miRNA ID } & \multirow[b]{2}{*}{ Sequence } & \multirow[b]{2}{*}{ Genomehits } & \multirow[b]{2}{*}{ Hairpinlength } & \multirow{2}{*}{ Hairpin Gc } & \multirow{2}{*}{ MFE } & \multirow{2}{*}{ star seq } & \multicolumn{12}{|c|}{ Normalized number of reads found in Nicotiana benthamiana ${ }^{1}$} \\
\hline & & & & & & & Seedling (1) & Seedling (2) & Root (1) & Root (2) & Leaf (1) & Leaf (2) & Stem (1) & Stem (2) & Flower (1) & Flower (2) & Leaf $^{87}$ & Seedling ${ }^{\text {nn }}$ \\
\hline Nb_miRC1_3p & TIGTCAGGCTTGTGATTCTCC & 9 & 170 & 31,8 & $-50,3$ & YES & 249,3 & 214,2 & 374,2 & 203,2 & 171,6 & 113,5 & 137,7 & 188,9 & 132,4 & 608,3 & 83,0 & 64,5 \\
\hline Nb_mirC2_3p & TETPATCTCAGTGTTGGCATG & 4 & 142 & 38,0 & $-58,4$ & YES & 216,8 & 229,3 & 241,1 & 95,0 & 106,6 & 104,6 & 110,6 & 181,1 & 88,8 & 444,0 & 93,1 & \\
\hline 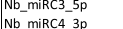 & 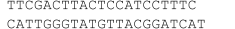 & $\begin{array}{l}2 \\
1\end{array}$ & ${ }_{81}^{144}$ & 38,2 & 每, 67,26 & 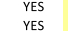 & $\begin{array}{l}14,7 \\
16,6\end{array}$ & $\begin{array}{l}54,9 \\
15,1\end{array}$ & $\begin{array}{l}3,4 \\
10,4\end{array}$ & $\begin{array}{l}2,0 \\
24,9\end{array}$ & 10,1 & 28,0 & $\begin{array}{l}9,3 \\
150\end{array}$ & 5,1 & $\begin{array}{l}2,1 \\
218\end{array}$ & $\begin{array}{l}0,0 \\
400\end{array}$ & $\frac{146,6}{24,9}$ & 38,7 \\
\hline 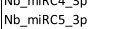 & 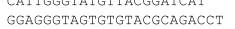 & $\frac{1}{6}$ & $\begin{array}{l}81 \\
206\end{array}$ & $\begin{array}{l}38,3 \\
45,1\end{array}$ & $\begin{array}{l}-47,2,2 \\
-103,8\end{array}$ & $\begin{array}{l}\text { YES } \\
\text { YES }\end{array}$ & $\begin{array}{c}16,6 \\
0,0\end{array}$ & $\begin{array}{l}1,1 \\
0,0\end{array}$ & $\begin{array}{l}1,4 \\
0,0\end{array}$ & ${ }_{0,0}^{24,9}$ & $\begin{array}{l}2,3 \\
1,1\end{array}$ & $2,1,1$ & $\begin{array}{l}1,0,0 \\
0,0\end{array}$ & $\begin{array}{ll}1 ., 1 \\
0,1\end{array}$ & $\begin{array}{l}2,8 \\
0,2\end{array}$ & $\begin{array}{c}4,0 \\
0,0\end{array}$ & $\begin{array}{l}24,9 \\
0,0\end{array}$ & 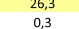 \\
\hline Nb_mircs_sp & ATGCGTACATATTACCTTCCC & 6 & 206 & 45,1 & - 103,8 & YES & , & $\begin{array}{l}0,0 \\
0,2\end{array}$ & , & 0,2 & $\begin{array}{l}1,1 \\
0,3\end{array}$ & $\begin{array}{l}2,1 \\
0,0\end{array}$ & , & , & 0,0 & , & 5,5 & , \\
\hline Nb_mirC6_-3p & GTATAATTATGCTAGAACTCCC & 13 & 110 & 40,9 & -55 & Yes & 7,8 & 14,3 & 0,8 & 5,1 & 10,4 & 15,4 & 8,5 & 6,7 & 4,0 & 3,8 & 24,0 & 16,4 \\
\hline Nb__mirC7_3p & AGAGAGACTGTTPACAAATAGACC & 9 & 71 & 49,3 & $-26,3$ & YES & 11,6 & 5,7 & 4,5 & 6,0 & 6,4 & 5,5 & 6,9 & 7,6 & 4,1 & 2,7 & 4,2 & 5,2 \\
\hline Nb_miRC8_3p_a & ATTATTGTCACCGATGTTGGGCCC & 12 & 204 & 49,0 & - $-177,8$ & YES & 3,8 & 2,6 & 2,5 & 1,6 & 2,7 & 0,7 & 3,6 & 2,6 & 2,8 & 5,8 & 1,3 & 1,4 \\
\hline $\begin{array}{l}\text { Nb_-mirC9.5p } \\
\text { Nb mirc10 3p }\end{array}$ & ATCAAACCAAATCATAGTCGGATT & 7 & $\begin{array}{l}72 \\
68\end{array}$ & $\begin{array}{l}37,0 \\
52,9\end{array}-10$ & $\begin{array}{l}-22,8,8 \\
-25,8\end{array}$ & $\begin{array}{l}\text { YES } \\
\text { YES }\end{array}$ & $\begin{array}{l}4,0 \\
5,0\end{array}$ & $\begin{array}{l}2,1 \\
0,0\end{array}$ & 6,7 & 0,9 & $\begin{array}{l}4,5 \\
24\end{array}$ & $\begin{array}{l}3,4 \\
21,4\end{array}$ & 0,8 & 2,1 & 1,5 & 0,0 & 2,9 & $\begin{array}{l}1,7 \\
0.8\end{array}$ \\
\hline 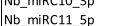 & 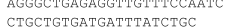 & $\begin{array}{l}6 \\
1\end{array}$ & 68 & $\begin{array}{l}52,9 \\
47,7\end{array}$ & $\begin{array}{l}-25,8 \\
-21,0\end{array}$ & $\begin{array}{l}\text { YeS } \\
\text { YES }\end{array}$ & $\begin{array}{l}5,0 \\
7,5\end{array}$ & $\begin{array}{l}0,0 \\
8,5\end{array}$ & $\begin{array}{l}3,1 \\
3,6 \\
\end{array}$ & $0 ., 9$ & $\begin{array}{l}2,4 \\
10,7\end{array}$ & $\begin{array}{l}2,1 \\
11,6\end{array}$ & $\begin{array}{l}1,6 \\
1,6\end{array}$ & $\begin{array}{l}0,7 \\
0,6\end{array}$ & $\begin{array}{l}1,9 \\
0,6\end{array}$ & $\begin{array}{l}1,5 \\
2,2\end{array}$ & $\begin{array}{l}0,0 \\
6,7\end{array}$ & .11, \\
\hline $\mathrm{Nb}$ b miRC12.5p & САТTGTAACATGTATCACTCA & 1 & 63 & 38,1 & ${ }_{-21,9}^{-2,9}$ & YeS & 0,0 & 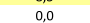 & 0,0 & 0,2 & 0 & 0,3 & 㞸, & o, & 然, & 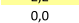 & 0,0 & 然, \\
\hline Nb_mirC13_3p & AGAGGACACCTCTATTTATAGGGA & 12 & 86 & 34,9 & $-23,4$ & YES & 0,6 & 3,2 & 1,1 & 4,6 & 2,1 & 4,1 & 7,3 & 4,4 & 5,4 & 0,0 & 5,1 & 3,1 \\
\hline Nb_mirC14_5p & TTAGATTTCATTCCTGTTGACT & 13 & 76 & 46,1 & $-26,0$ & YES & 1,3 & 0,7 & 2,2 & 4,4 & 0,3 & 0,3 & 5,7 & 3,2 & 4,0 & 2,6 & 0,0 & 0,6 \\
\hline & ICGTGTGGAGRAATGTTGTGG & 2 & 90 & 37,8 & $\begin{array}{l}-60,9 \\
-507\end{array}$ & YES & 0,0 & 0,9 & 0,0 & 0,0 & 5,1 & 1,0 & 2,8 & 0,7 & 0,3 & 0,0 & 0,0 & 2,2 \\
\hline Nb_mirc16_3p & $\begin{array}{l}\text { ITTGGGACAMAAGTCACCAAC } \\
\text { GGGAGGAGCCGGGTCTATTTT }\end{array}$ & $\begin{array}{c}3 \\
14\end{array}$ & 123 123 & $\begin{array}{l}41,5 \\
50,5\end{array}$ & $\begin{array}{l}-59,7 \\
-562\end{array}$ & $\begin{array}{l}\text { YES } \\
\text { YES }\end{array}$ & 7,2 & $\begin{array}{l}3,8 \\
0,0\end{array}$ & 2,8 & $\begin{array}{l}3,7 \\
0,0\end{array}-x-3$ & 5,6 & $\begin{array}{l}8,9 \\
0.0\end{array}$ & $\begin{array}{l}0,0 \\
0,0\end{array}$ & $\begin{array}{l}0,9 \\
0,0\end{array}$ & 2,3 & 0,0 & 8,4 & 5,9 \\
\hline No_mirC18_3p & TITTCGGAAACCTAATAACTT TI & 3 & 209 & 39,2 & 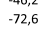 & YES & 0,6 & 2,2 & 5,0 & & 0,0 & 0,0 & 0,4 & 0,2 & o, & $\begin{array}{l}23,2 \\
23,2\end{array}$ & 3,8 & 0,0 \\
\hline & & & & & & & & & & & & & & & & & & \\
\hline
\end{tabular}

Fig. 5 Novel miRNAs in N. benthamiana. Normalized read numbers of novel miRNAs across the tissues included in this study. Expression profiles are expressed in reads per million genome matching reads. Heat map colours represents absolute normalized levels of miRNA expression ranging from less than 1 RPM (white) to more than 1000 RPM (red) as indicated in the colour key

the 24 nucleotides being the most abundant variants (Nb_miRC5_3p and Nb_miRC9_5p) (Fig. 6a).

Next we checked the 5 '-nucleotide distribution of the new miRNA families in our libraries. Seven started with uracil at their 5'-end (Nb_miRC16_3p, Nb_miRC14_5p, Nb_miRC1_3p, Nb_miRC18_3p, Nb_miRC15_5p, Nb_ miRC3_5p and Nb_miRC2_3p) (Fig. 6b). Eight miRNA families exhibited a preference for an adenine at position 1 , although six of these have a different nucleotide composition at position 1 to a variable degree (NB_miRC9_5p, NB_miRC5_3p, NB_miRC8_3p_a, NB_miRC13_3p, NB_
miRC7_3p and NB_miRC10_3p). In three miRNA families the most frequently found first nucleotide at their 5 '-end was cytosine (Nb_miRC11_5p, Nb_miRC4_3p and $\mathrm{Nb}$ miRC12_5p). One miRNA family exhibited a preference for a guanine at position 1, although a significant fraction has uracil at the $5^{\prime}$-position (Nb_miRC6_3p) (Fig. 6b). Although the majority of plant miRNAs have a uracil at position 1 , it is not unusual that some miRNA families contain adenine, cytosine and even guanine in significant proportions at the $5^{\prime}$-position [15].

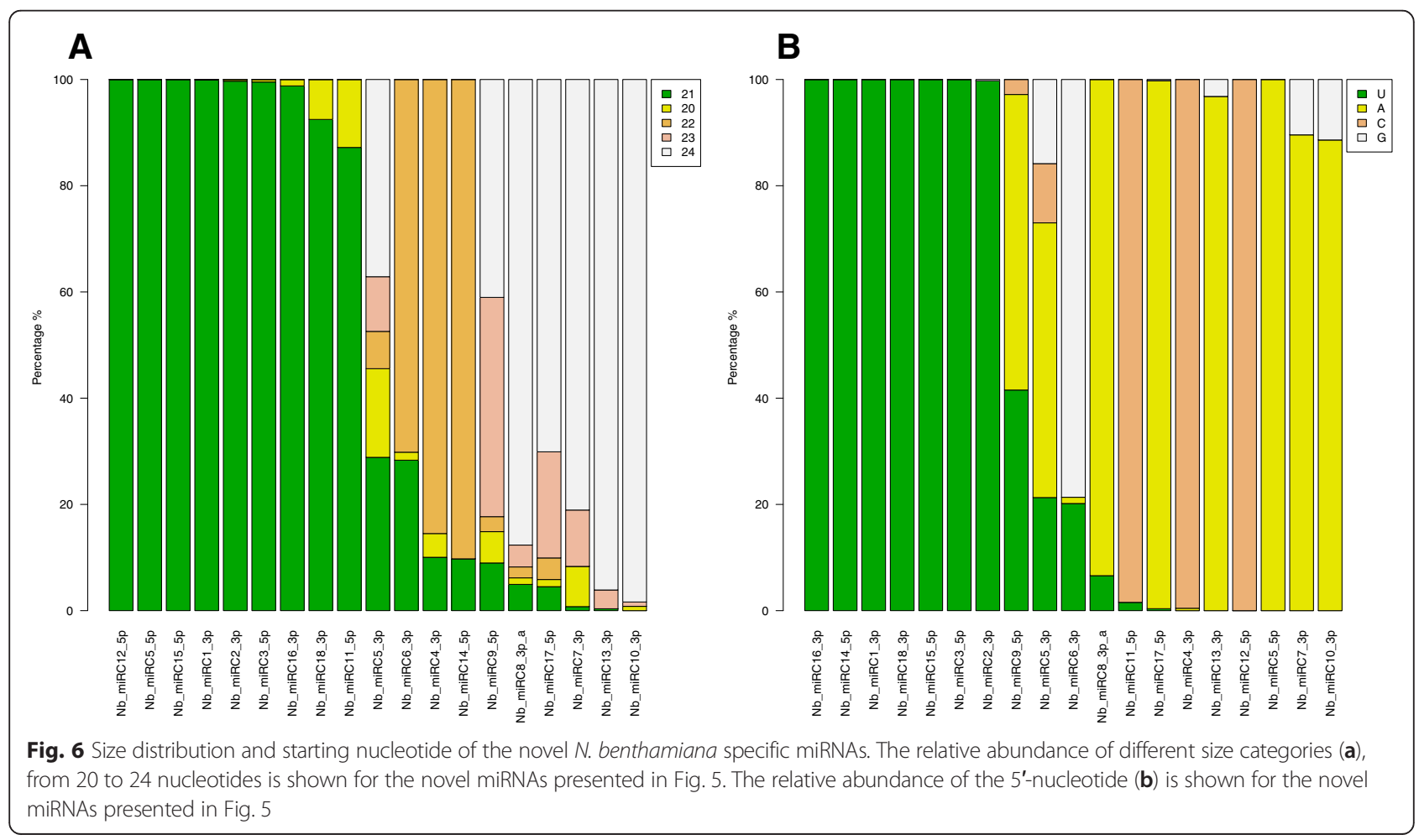


Young miRNAs are often weakly expressed, processed imprecisely or lack targets [16]. Our data fits well with these previous observations since most of the $N$. benthamiana specific miRNAs showed low relative abundance in our libraries (below 25 RPM; except Nb_miRC1_3p, $\mathrm{Nb}$ _miRC2_3p and Nb_miRC3_5p) and in several cases they were accompanied by additional size classes for various degrees. Furthermore, some of the new miRNAs identified in our sRNA libraries are produced from long hairpin precursors that may also indicate the young evolutionary origin (Nb_miRC2_3p, Nb_miRC3_5p, Nb_miRC5_3p, Nb_miRC8_3pa and Nb_miRC18_3p) (Additional file 5: Figure S3). This situation is well observable on the
$\mathrm{Nb}$ miRC8 precursor where two miRNA duplexes were both identified in the sRNA libraries and detected by Northern blots (Additional file 6: Figure S4). However, we did not identify miRNAs without target mRNAs in our data set, since we used the presence of cleaved target mRNA as a criterion to select new miRNAs.

We used Northern blot analysis to check the expression level of $N$. benthamiana specific miRNAs in five tissues (seedling, root, leaf, stem and flower). The miRNAs that gave signal on the Northern blot, in most cases were detectable in all of the tissues tested (Fig. 7). Some of the new miRNAs were abundant in specific tissues (Nb_miRC10_3p in stem and flower; Nb_miRC16_3p in

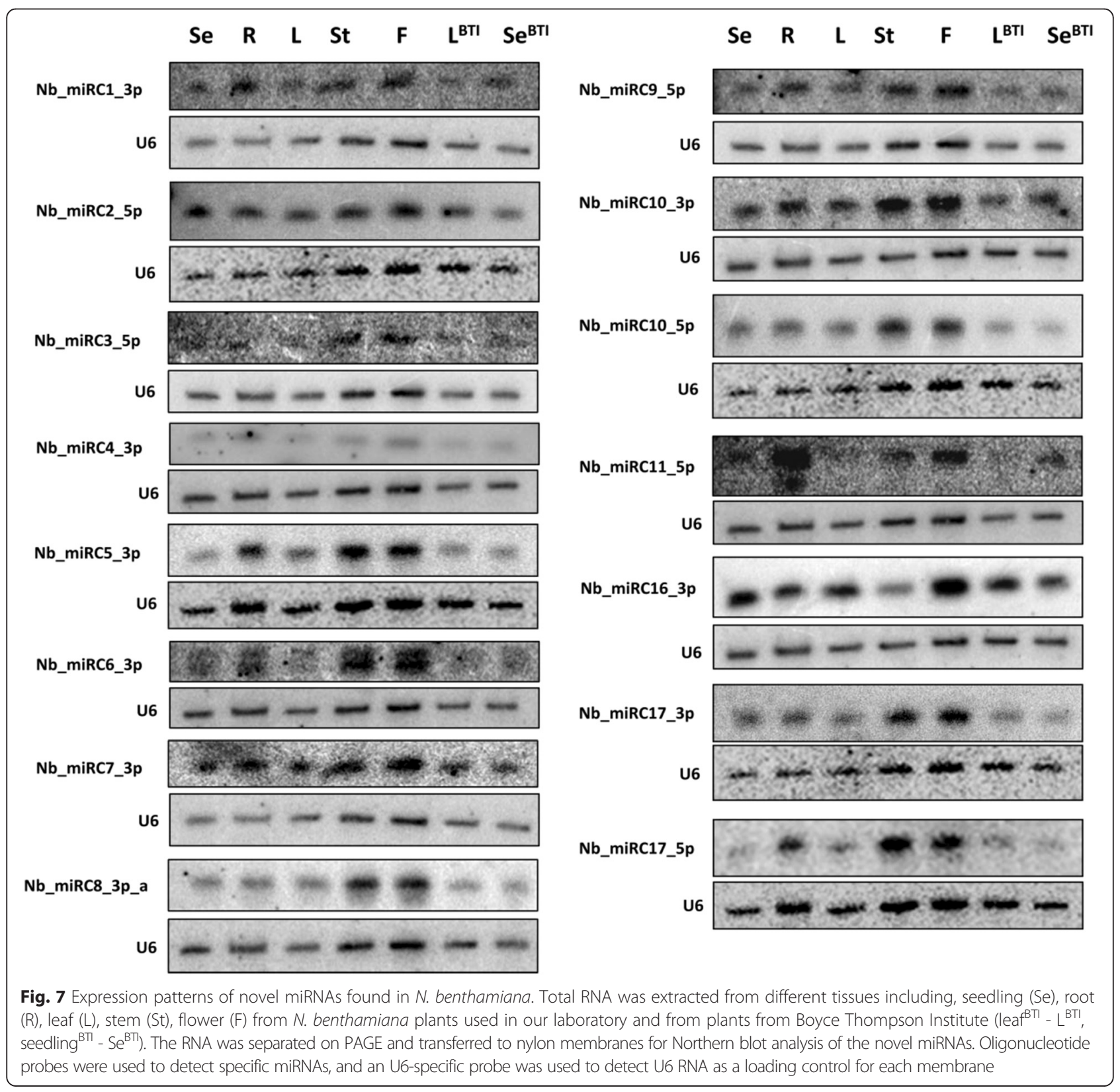


seedling and flower), and many of them showed differential expression in the tissues analysed (Nb_miRC1_3p, Nb_miRC2_5p, Nb_miRC10_3p, Nb_miRC11_5p and $\mathrm{Nb}$ _miRC16_3p) (Fig. 7). The relative number of reads in all tissues was very low for most of the miRNAs (Nb_miRC1_3p, Nb_miRC2_3p and Nb_miRC3_5p was an exception) and this was also reflected in the Northern blot analysis, since we did not obtain signal for six miRNAs (Nb_miRC5_5p, Nb_miRC12_5p, Nb_miRC13_3p, Nb_miRC14_5p, Nb_miRC15_5p and Nb_miRC18_3p). The expression profiles obtained by Northern blot analysis were different from the sequencing data for Nb_miRC3_5p, Nb_miRC6_3p, Nb_miRC8_3pa, Nb_miRC11_5p and Nb_miRC17_5p. However, for the other new miRNAs (Nb_miRC1_3p, Nb_miRC7_3p, Nb_miRC9_5p and $\mathrm{Nb} \_$miRC10_3p), sequencing data and expression profiles obtained by Northern blot analysis showed good correlation (Fig. 5 and Fig. 7). Although the relative read numbers for most of the new miRNAs were low, we were able to confirm the presence of $13 \mathrm{~N}$. benthamiana specific miRNAs by Northern blot.

\section{Targets of $N$. benthamiana specific miRNAs}

We identified 32 targets for new miRNAs using our degradome libraries. Interestingly, in the case of Nb_miRC5 we found target for both the mature and the star strand of the new miRNA (Table 3; Additional file 7: Figure S5; Additional file 8: Table S3). Based on the degradome data, among the identified target mRNAs of the specific, new $N$. benthamiana miRNAs, three were classed as category 0 , two as category 1 , twenty-two as category 2 and five as category 3. Comparing the target list of the known (conserved and non-conserved) and new miRNAs the most obvious difference between them is that the known miRNA targets mostly belong to category 0 and 1 (Tables 2 and 3 ). Based on their molecular function both groups regulate various genes that are included in transcriptional regulation or enzymatic activity (Additional file 9: Figure S6.).

The new miRNAs target different genes with a wide variety of predicted functions. One of the three identified category 0 targets of the new miRNAs is the mRNA of the heterotrimeric GTP binding protein (G proteins) alpha subunit (targeted by Nb_miR17_5p). G proteins are highly conserved in eukaryotes. Plant $\mathrm{G}$ proteins play an important regulatory role in multiple physiological processes. They are involved in signal transduction from hormone receptors, including the plant hormones gibberellin and abscisic acid that regulate gene expression; secretion, defence, stomata movements, channel regulation, sugar sensing and cell death [44]. The heterotrimeric G protein complex is minimally composed of three subunits: alpha, beta and gamma. Plants have only a small number of genes encoding the $\mathrm{G}$ proteins subunits. Arabidopsis has only one canonical G protein alpha subunit, one beta subunit and three gamma subunit [45]. Plant alpha subunits are highly conserved between species, it binds and hydrolyse GTP and relay signals by interacting with downstream effector proteins [46]. Interestingly, during convergent evolution human $\mathrm{G}$ protein alpha-13 (GNA13) expression is also regulated by miRNA (miR-31) in breast cancer cells [47].

Another category 0 target is the mRNA of Peroxisome Biogenesis Factor 10 (PEX10). It is cleaved by Nb_mi RC5_3p and has been demonstrated to be a component of the peroxisomal matrix protein import machinery. Peroxisomes are eukaryotic organelles and they are involved in a wide range of processes. Plant peroxisomes are important in primary and secondary metabolism, development, and responses to abiotic and biotic stresses. Previous studies identified 22 PEX genes in the Arabidopsis genome and demonstrated that they play a pivotal role in the import of peroxisomal matrix proteins [48]. PEX 10 perform multiple functions, including the biogenesis of ER-derived protein and oil bodies [49], the maintenance of ER morphology, the formation of cuticular wax [50], peroxisome and chloroplast connections [51].

One of the category 1 targets is REPRESSOR OF SILENCING (ROS1) which is cleaved by Nb_miRC1_3p. Interestingly, the sequence of $\mathrm{Nb} \_m i R C 1 \_3 p$ can also be found in Nicotiana attenuata [43] and its target site on ROS1 is conserved in other Nicotiana species as well. ROS1 encodes a nuclear DNA glycosylase domain protein that catalyse the release of 5-methylcytosine $(5-\mathrm{meC})$ from DNA via a base excision repair reaction [52]. DNA cytosine methylation is an important epigenetic mark conserved in many eukaryotes. It has important roles in transposon silencing, genome organization, genomic imprinting and regulation of gene expression [53]. During continuous adaptation to variable external and internal environments DNA methylation patterns are dynamically controlled by methylation and demethylation reactions. ROS1 plays an important role in active DNA demethylation and helps to maintain gene expression $[54,55]$. The targeting of ROS1 by a miRNA provides a new regulatory layer to reinforce transcriptional gene silencing by a post-transcriptional repression of its activity. The targeting of a DNA glycosylase (DEMETER-LIKE protein3) by a miRNA (miR402) was first predicted in Arabidopsis [56] and later it was shown that the expression of DEMETER-LIKE protein3 mRNA was down-regulated in miR402-overexpressing transgenic plants [57].

The other category 1 target is a zinc-regulated transporter (ZRT), iron-regulated transporter (IRT)-like protein 1 (ZRT/IRT-like protein 1) and is cleaved by NB-miRC12_5p. ZRT/IRT-like protein family has been demonstrated to be involved in metal uptake and transport. ZRT/IRT-like proteins generally contribute to metal ion homeostasis by transporting cations into the cytoplasm [58]. It has been reported in several plant species that various miRNAs are 
Table 3 Targets of novel miRNAs found in Nicotiana benthamiana

\begin{tabular}{|c|c|c|c|c|c|c|}
\hline new miRNA ID & Gene ID & $\begin{array}{l}\text { Cleavage } \\
\text { position }\end{array}$ & Category & $\begin{array}{l}\text { Alignment } \\
\text { score }\end{array}$ & $\begin{array}{l}\text { Normalized } \\
\text { abundance }^{\mathrm{a}}\end{array}$ & Annotation \\
\hline Nb_miRC1_3p & comp79937_c1_seq1 312_1058 & 862 & 3 & 3,5 & 0,2 & Elongation factor 1-alpha 4 \\
\hline Nb_miRC1_3p & comp78325_c0_seq3 335_2797 & 1128 & 1 & 1,0 & 0,2 & Protein ROS1 \\
\hline Nb_miRC2_3p & comp75577_c0_seq17 1347_1982 & 405 & 2 & 4,0 & 1,2 & $\begin{array}{l}\text { Down syndrome critical region } \\
\text { protein } 3 \text { homolog }\end{array}$ \\
\hline Nb_miRC3_5p & comp79768_c0_seq4 287_3412 & 1868 & 2 & 3,5 & 1,1 & Elongation factor Ts \\
\hline Nb_miRC4_3p & comp76033_c0_seq2 367_1701 & 917 & 2 & 4,0 & 1,9 & $\begin{array}{l}\text { CBL-interacting serine/threonine- } \\
\text { protein kinase } 5\end{array}$ \\
\hline Nb_miRC5_3p & comp73317_c0_seq28 1673_2236 & 2967 & 0 & 3,5 & 2,1 & Peroxisome biogenesis factor 10 \\
\hline Nb_miRC5_3p & comp69461_c0_seq1 371_982 & 1380 & 2 & 0,5 & 0,2 & Protein CREG1 \\
\hline Nb_miRC5_3p & comp76292_c1_seq18 500_808 & 1632 & 2 & 1,5 & 0,2 & Probable WRKY transcription factor 53 \\
\hline Nb_miRC5_3p & comp72235_c0_seq2 239_1444 & 1720 & 2 & 2,5 & 0,3 & $\begin{array}{l}\text { Cytochrome b561 and DOMON } \\
\text { domain-containing } \\
\text { protein At5g47530-like }\end{array}$ \\
\hline Nb_miRC5_5p & comp70843_c0_seq1 178_1023 & 528 & 2 & 4,0 & 1,4 & Protein TIC 21, chloroplastic \\
\hline Nb_miRC6_3p & comp75362_c2_seq1 7645_8472 & 2399 & 2 & 3,5 & 0,2 & $\begin{array}{l}\text { G-type lectin S-receptor-like serine/ } \\
\text { threonine-protein } \\
\text { kinase At1g11330 }\end{array}$ \\
\hline Nb_miRC7_3p & comp73495_c0_seq6 312_1019 & 1288 & 2 & 3,5 & 1,4 & Proteasome subunit alpha type-2-A \\
\hline Nb_miRC7_3p & comp56753_c0_seq1 215_457 & 517 & 0 & 2,0 & 5,5 & WAT1-related protein At5g40240-like \\
\hline Nb_miRC8_3p_a & comp71383_c0_seq6 99_857 & 1317 & 3 & 2,5 & 0,6 & Aquaporin TIP1-3 \\
\hline Nb_miRC8_3p_a & comp75266_c2_seq4 3193_3486 & 3454 & 2 & 1,0 & 0,7 & $\begin{array}{l}\text { Probable isoaspartyl peptidase/ } \\
\text { L-asparaginase } 3\end{array}$ \\
\hline Nb_miRC9_5p & comp71496_c0_seq1 489_1463 & 462 & 2 & 4,0 & 0,2 & $\begin{array}{l}\text { Serine/threonine-protein phosphatase } \\
2 \mathrm{~A} \text { regulatory } \\
\text { subunit B" subunit alpha }\end{array}$ \\
\hline Nb_miRC9_5p & comp64986_c0_seq1 125_487 & 1232 & 2 & 2,5 & 0,2 & 605 ribosomal protein L34 \\
\hline Nb_miRC10_3p & comp77607_c3_seq4 3_1151 & 2317 & 2 & 4,0 & 0,2 & Suberization-associated anionic peroxidase \\
\hline Nb_miRC10_3p & comp80078_c3_seq4 193_2097 & 2131 & 2 & 1,0 & 1,1 & Formate-tetrahydrofolate ligase \\
\hline Nb_miRC10_3p & comp72702_c0_seq4 152_2431 & 2575 & 3 & 2,0 & 1,0 & Beta-amyrin synthase \\
\hline Nb_miRC11_5p & comp82078_c0_seq1 3_1277 & 938 & 2 & 3,5 & 2,7 & Threonine deaminase \\
\hline Nb_miRC11_5p & comp78978_c0_seq3 374_2785 & 2557 & 2 & 3,0 & 0,4 & \\
\hline
\end{tabular}


Table 3 Targets of novel miRNAs found in Nicotiana benthamiana (Continued)

\begin{tabular}{|c|c|c|c|c|c|c|}
\hline Nb_miRC11_5p & comp89465_c0_seq1 218_1237 & 532 & 3 & 4,0 & 0,2 & Ervatamin-B-like \\
\hline Nb_miRC12_5p & comp79295_c0_seq1 283_3321 & 3114 & 2 & 3,5 & 2,7 & $\begin{array}{l}\text { Probably inactive leucine-rich repeat } \\
\text { receptor-like } \\
\text { protein kinase At3g28040 }\end{array}$ \\
\hline Nb_miRC12_5p & comp56752_c0_seq1 & 568 & 1 & 3,5 & 0,7 & ZRT/IRT-like protein 1 \\
\hline Nb_miRC13_3p & comp77835_c0_seq3 61_621 & 797 & 2 & 2,5 & 0,3 & Disease resistance response protein 206 \\
\hline Nb_miRC14_5p & comp74263_c0_seq1 230_2029 & 966 & 2 & 4,0 & 3,8 & Chaperonin 60 subunit beta 2, chloroplastic \\
\hline Nb_miRC15_5p & comp78088_c1_seq1 1536_2366 & 3251 & 3 & 4,0 & 0,7 & Peroxisome biogenesis protein 19-1 \\
\hline Nb_miRC15_5p & comp85070_c0_seq1 3_2648 & 2151 & 2 & 2,5 & 1,0 & $(\mathrm{E}, \mathrm{E})$-geranyllinalool synthase \\
\hline Nb_miRC16_3p & comp88815_c0_seq1 2_1909 & 1845 & 2 & 2,5 & 0,9 & Polyphenol oxidase, chloroplastic \\
\hline Nb_miRC17_5p & comp63365_c1_seq3 3_242 & 29 & 0 & 1,0 & 1,3 & $\begin{array}{l}\text { Heterotrimeric GTP binding protein } \\
\text { alpha subunit }\end{array}$ \\
\hline Nb_miRC18_3p & comp67145_c0_seq1 106_930 & 361 & 2 & 3,5 & 2,0 & $50 S$ ribosomal protein L3, chloroplastic \\
\hline
\end{tabular}

a The abundance for the degradome fragment (tag) indicating cleavage at that position/total number of fragments $\times 1,000,000$ 
vital for maintaining nutrient homeostasis by regulating the expression of transporters that are involved in nutrient uptake and mobilization [59].

Other targets that are worthy to note are the WAT1related protein At5g40240-like gene targeted by $\mathrm{Nb}$-mi RC7_3p; the CBL-interacting serine/threonine-protein kinase gene targeted by $\mathrm{Nb}$ _miRC4_3p, proteasome subunit alpha type-2-A gene targeted by Nb_miRC7_3p, suberization-associated anionic peroxidase targeted by $\mathrm{Nb}$ _miRC10_3p and beta-amyrin synthase targeted by Nb_miRC10_3p.

\section{Conclusions}

In this study we have confirmed the expression of known and new miRNAs in various tissues of $N$. benthamiana using high-throughput sequencing and Northern blot analysis. As a result, this work represents a tissue specific atlas of known and new miRNA expression of $N$. benthamiana. In addition, we have experimentally identified many targets of both known and new miRNAs using a highthroughput method for the global identification of miRNAs targets. This study provides a valuable resource of miRNAs and their validated target mRNAs to the plant research community that will be beneficial well into the future.

\section{Methods}

\section{Plant materials}

Wild-type Nicotiana benthamiana plants and Nicotiana benthamiana plants from Boyce Thompson Institute were grown in soil or, for seedling and root samples, on half-strength Murashige and Skoog plates under standard growth conditions at $24{ }^{\circ} \mathrm{C}$ with $16 \mathrm{~h}$ of illumination per day. Total RNA was extracted from 14 day old seedlings and root tissues grown on plates. Furthermore total RNA was also extracted from leaves, stems and flowers without sepals collected from plants grown in soil. Total RNA was isolated by using the phenol/chloroform extraction method [60]. The quality and the quantity of the isolated total RNAs were checked using a nanodrop spectrophotometer and the integrity of RNAs was checked via non-denaturing agarose gel electrophoresis.

\section{RNA sequencing (RNA-Seq) library preparation for Solexa sequencing}

cDNA library for RNA-Seq was generated from $1 \mu \mathrm{g}$ total RNA using TruSeq RNA Sample Preparation Kit (Illumina, San Diego, CA, USA) according to the manufacturer's protocol. Briefly, poly-A tailed RNAs were purified by oligodT conjugated magnetic beads and fragmented on $94{ }^{\circ} \mathrm{C}$ for $8 \mathrm{~min}$, then 1 st strand cDNA was transcribed using random primers and SuperScript II reverse transcriptase (Lifetechnologies, Carslbad, CA, USA). Following this step second strand cDNA were synthesized, then double stranded cDNA molecules were end repaired and 3 ' ends adenylated then Illumina index adapters were ligated. After adapter ligation step enrichment PCR was performed to amplify the adapter-ligated cDNA fragments. Fragment size distribution and molarity of libraries were checked on Agilent BioAnalyzer DNA1000 chip (Agilent Technologies, Santa Clara, CA, USA). 10pM of denatured libraries were used for cluster generation on cBot instrument, and then sequencing run was performed on Illumina HiSeq 2000 instrument (100 bp paired-end) (Illumina, San Diego, CA, USA).

\section{Small RNA sequencing libraries for Solexa sequencing}

The small RNA cDNA libraries were constructed using the Small RNA Sample Prep Kit (Illumina, CA, US), according to the manufacturer's instructions. Briefly, $1 \mu \mathrm{g}$ of total RNA from wild-type Nicotiana benthamiana samples, including, seedling, root, leaf, stem and flower were ligated to Solexa adaptors and then converted to cDNA by RT-PCR. The resulting cDNAs were then amplified by PCR, gel-purified and submitted for Illumina/Solexa sequencing. High-throughput sequencing was performed using HiScan SQ platform (50 bp single-end).

\section{Degradome cDNA libraries for Solexa sequencing}

The degradome cDNA library was prepared using a total RNA from wild-type Nicotiana benthamiana samples, including, seedling, root, leaf, stem and flower following the procedures previously described by German et al. [39]. Conversely to the small RNA libraries, the degradome cDNA library was sequenced with a custom-made sequencing primer (5'-CCACCGACAGGTTCAGAGTTCTACA GT-3') [36] on HiScan SQ platform (50 bp single-end).

\section{Northern blot analysis}

A total amount of $5 \mu \mathrm{g}$ of RNA from each Nicotiana benthamiana tissues (seedling, root, leaf, stem, flower, leaf BTI, seedling BTI) were individually separated on a 8 M UREA/12 \% polyacrylamid $1 \times$ TBE gel. After gel run we transferred the RNAs from dPAGE onto the neutral nylon membrane, Hybond NX (Amersham/GE Healthcare) by semi-dry electroblotter. The transferred molecules were cross-linked by the enhanced sensitivity 1-ethyl-3-(3-dimethylaminopropyl) carbodiimide (EDC) chemical cross-linking method at $60{ }^{\circ} \mathrm{C}$ for $90 \mathrm{~min}$ as described previously by Pall et al. [61]. The membranes were prehybridized at $38{ }^{\circ} \mathrm{C}$ for $1 \mathrm{~h}$ in ULTRAhyb ${ }^{\circ} \mathrm{Ul}-$ trasensitive Hybridization Buffer (Ambion/thermo Scientific). DNA oligo probes were end labelled by the forward reaction using T4 polynucleotide kinase (Thermo Scientific) and $\left[\gamma^{32} \mathrm{P}\right]$ ATP for $1 \mathrm{~h}$ at $37{ }^{\circ} \mathrm{C}$. Hybridization was performed at $40{ }^{\circ} \mathrm{C}$ overnight. Each membrane was stripped than rehybridized with different probes (The sequences of the used probes are available 
in Additional file 10: Table S4.). The membranes were exposed to a phosphorimager.

\section{Real-time PCR quantification of miRNAs}

We also used real-time looped RT-qPCR procedure for detection and quantification of miRNAs. Stem-loop RT primers and forward qPCR primers were designed according to Chen et al. [62]. (The sequence data is aviable in Additional file 10: Table S4). As internal reference gene, nucleolar small RNA U6 was used [63]. We followed the protocol by Varkonyi-Gasic et al. [64] with optimalisation to our samples. For DNase treatment of the RNA samples 3 units of DNase I (Thermo Scientific) were used to $250 \mathrm{ng}$ total RNA from the different tissues represented in this study. After $30 \mathrm{~min}$ incubation at $37^{\circ} \mathrm{C}$, a phenol/chloroform extraction was performed to inactivate the enzyme and purificate the template. For the elution $20 \mu \mathrm{l}$ MQ water was used. In the next step, a multiplexed cDNA synthesis of U6 and miRNA was performed. Stem-loop pulsed reverse transcription protocol was performed in a $20 \mu \mathrm{l}$ reaction volume with each sample for RT and NO RT reactions $(0.5 \mu \mathrm{l}(10 \mathrm{mM})$ dNTP's, $1-1 \mu \mathrm{l}$ $(1 \mu \mathrm{M})$ U6 reference and miRNA specific primer and MQ water was mixed and heated to $65^{\circ} \mathrm{C}$ for $5 \mathrm{~min}$ and incubate on ice for $2 \mathrm{~min}$. Then 4 units of RNaseOUT (Invitrogen), 50 units of RevertAid H- Reverse transcriptase, $4 \mu \mathrm{l}$ $5 x$ RT Buffer (Thermo Scientific) and $1 \mu$ RNA template from the previous DNase treatment the was added to the reaction tubes.). The pulsed $\mathrm{RT}$ was preformed in thermo cycler: $30 \mathrm{~min}$ at $16{ }^{\circ} \mathrm{C}$ incubation, followed by pulsed RT of 60 cycles at $30{ }^{\circ} \mathrm{C}$ for $30 \mathrm{~s}, 42{ }^{\circ} \mathrm{C}$ for $30 \mathrm{~s}$ and $50{ }^{\circ} \mathrm{C}$ for $1 \mathrm{~s}$, then at $85{ }^{\circ} \mathrm{C}$ for $5 \mathrm{~min}$ to inactivate the enzymes. To test the primer specificity and cDNA quality end-point PCR was performed with Pfu polymerase (Thermo Scientific) by 40 cycles following the Várkonyi-Galic et al. protocol. To perform real-time PCR the following components were used: $5 \mu \mathrm{l} 2 \mathrm{x}$ FastStart Essential DNA Green Master Mix (Roche), 0,5 $\mu \mathrm{l}(10 \mu \mathrm{M})$ forward primer, 0,5 $\mu \mathrm{l}(10 \mu \mathrm{M})$ Universal reverse primer, $3 \mu \mathrm{l}$ water and $1 \mu \mathrm{l}$ RT product. PCR tubes were incubated at $95{ }^{\circ} \mathrm{C}$ for $10 \mathrm{~min}$, followed by a 2 Step amplicifation by 40 cycles of $95{ }^{\circ} \mathrm{C}$ for $15 \mathrm{~s}, 60{ }^{\circ} \mathrm{C}$ for $60 \mathrm{~s}$. For melting curve analysis, the samples were denaturated at $95^{\circ} \mathrm{C}$ for $10 \mathrm{~s}, 65^{\circ} \mathrm{C}$ for $60 \mathrm{~s}, 97^{\circ} \mathrm{C} 1 \mathrm{~s}$, then cool to $37^{\circ} \mathrm{C}$ in a Roche LightCycles 96 instrument. To analyse results the LightCycler software was used.

\section{Small RNA processing}

Raw sequence reads quality check was performed using FastQC (version 0.11.3). For adaptor trimming cutadapt (version 1.2.1) was used with the following parameters: minimal sequence length after adaptor removal was 16, maximal sequence length was 28 [65]. We used UEA Small RNA Workbench (version 2.5.0) for all miRNA processing tasks [66]. MiRProf calculated the expression of known miRNAs. This program uses Mirbase (version 20). We allowed 2 mismatches during the analysis. We grouped together mismatches, variants and miRNAs from different organisms and worked only with families. MirCat identified candidant microRNAs. We used the default plant specific parameters. PAREsnip was used to process degradome sequences for finding microRNA targets [40] (Additional file 11). During this analysis, we discarded results from category 4, the maximal mismatch number was 4, mismatches at position 10-11 were not allowed and more than two mismatches at adjacent positions also not allowed. Every other parameter was the default. We have created a non-redundant scaffold set from the available $N$. benthamiana genome sequencing projects using Blast. We used this set as genome in all programs where genome sequence was a mandatory requirement. Results from these programs were analysed further with custom made Perl and Python scripts. For statistical analysis and visualization $\mathrm{R}$ was used [67].

\section{Transcript processing and annotation}

To generate the corresponding mRNA transcriptome we have sequenced Illumina paired end TruSeq libraries from the same $N$. benthamiana leaf, stem, germ, root, flower and seed samples as at the small RNAs. We pooled together 315 million 2x100 bp reads and used Trinity de novo assembly program (r2013-02-16) with default parameters [68].

To find biological function for de-novo transcripts, Trinotate was used (version: 20130225) according to the manual [68]. All related data were pushed into an SQLight database for further processing.

To perform the Gene Ontology (GO) analysis of miRNA targets the agriGO web-based tool and database version 1.2 was used [69]. The analysis setting was the following: Singular Enrichment Analysis (SEA) with the Arabidopsis thaliana TAIR9 reference gene model. The graphical results showing the molecular functions.

\section{Data access}

The RNA-seq, sRNA and degradome data discussed in this publication have been deposited in National Center for Biotechnology Informations (NCBI) BioProject database under Accession number: PRJNA288746.

\section{Additional files}

Additional file 1: Table S1. MFEl values of conserved and other known miRNAs in Nicotiana benthamiana. (XLSX $18 \mathrm{~kb}$ )

Additional file 2: Figure S1. Quantification of miRNAs by RT-qPCR. Validation of (A) Nb-miRNA167 and (B) Nb-miR482 expression by RTqPCR. Northern blot validation of conserved miRNAs (Fig. 4.) compared 
to RT-qPCR quantification. In both experiments the reference gene was U6. (PDF $134 \mathrm{~kb}$ )

Additional file 3: Figure S2. Target plots (t-plots) of conserved and other known miRNA targets confirmed by degradome sequencing. In the head of the pictures there is a unique identifier of the mRNA followed by the annotation of the transcript. The solid lines and dot in miRNA: mRNA alignments indicate matched RNA base pairs and GU mismatch, respectively. The relative abundances are plotted against the nucleotide position within the transcript. (PDF $377 \mathrm{~kb}$ )

Additional file 4: Table S2. Targets of conserved and other known miRNAs in samples. (XLSX $44 \mathrm{~kb}$ )

Additional file 5: Figure S3. Secondary structures of knew N. benthamiana specific miRNAs found in our liraries. The $5^{\prime}$ end of the RNA is marked by a circle. Candidant miRNAs are highlighted with different colours. Image was generated by RNAfold/RNAplot on The University of East Anglia sRNA toolkit (plant version). (PDF $219 \mathrm{~kb}$ )

Additional file 6: Figure S4. Nb_miRC8 precursor. A) Secondary structure for Nb miRC8. The $5^{\prime}$ end of the RNA is marked by a circle. The candidant miRNAs labelled with different colours. B) Northen blot expressions for the two Nb_miRC8 candidants (Nb_miRC8_3p_a, Nb_miRC8_3p_b). An U6-specific probe was used to detect U6 RNA as a loading control for each membrane. (PDF 398 kb)

Additional file 7: Figure S5. Target plots (t-plots) of $N$. benthamiana specific knew miRNA targets confirmed by degradome sequencing. In the head of the pictures there is a unique identifier of the mRNA followed by the annotation of the transcript. The solid lines and dot in miRNA: mRNA alignments indicate matched RNA base pairs and GU mismatch, respectively. The relative abundances are plotted against the nucleotide position within the transcript. (PDF $364 \mathrm{~kb}$ )

Additional file 8: Table S3. Targets of novel Nicotiana benthamiana specific miRNAs in samples. (XLSX $25 \mathrm{~kb}$ )

Additional file 9: Figure S6. Gene Ontology (GO) analysis of miRNA target mRNAs. Functional annotation of known and $N$. benthamiana specific miRNA target mRNAs based on their molecular functions. (PDF $140 \mathrm{~kb}$ )

Additional file 10: Table S4. Oligonucleotide sequences used for probes in Northern blot analysis and RT-PCR validation. (XLSX $11 \mathrm{~kb}$ )

Additional file 11: This file lists the complete mRNA sequences of miRNA targets found in our samples in fasta formats. (PDF $416 \mathrm{~kb}$ )

\section{Competing interests}

The author(s) declare that they have no competing interests.

\section{Authors' contributions}

IB carried out RNA extractions, the Northern Blot experiments, performed high throughput library preparation and participated in bioinformatics work and data analysis. TN and EB carried out the bioinformatics analyses. This study was designed by GS, JB, DS, VE and ZH and organized by GS, IB, JB, EB, $D S, V E$ and $Z H$. The data was analysed and interpreted by GS. GS wrote the manuscript and all authors critiqued the manuscript for important intellectual content. All authors read and approved the final manuscript.

\section{Acknowledgements}

This work has been supported by OTKA grants to GS (K-101793; K-106170), JB (NK105850), DS (K-109835), EV (K-108718) and ZH (K-109438) and by the Hungarian Ministry of Agriculture to EB and TN (grant number NAIK-MBK M71411). We would like to thank the help of Andor Auber with the RT-qPCR experiment. We are thankful for Douglas Pyott and Attila Molnar for critically reading the manuscript.

Received: 23 July 2015 Accepted: 12 November 2015 Published online: 01 December 2015

\section{References}

1. Bombarely A, Rosli HG, Vrebalov J, Moffett P, Mueller LA, Martin GB. A draft genome sequence of Nicotiana benthamiana to enhance molecular plantmicrobe biology research. Mol Plant-Microbe Interact. 2012;25(12):1523-30.
2. Goodin MM, Zaitlin D, Naidu RA, Lommel SA. Nicotiana benthamiana: Its history and future as a model for plant-pathogen interactions. Mol Plant Microbe In. 2008;21(8):1015-26.

3. Silhavy D, Burgyan J. Effects and side-effects of viral RNA silencing suppressors on short RNAs. Trends Plant Sci. 2004;9(2):76-83.

4. Petre B, Saunders DG, Sklenar J, Lorrain C, Win J, Duplessis S, et al. Candidate Effector Proteins of the Rust Pathogen Melampsora larici-populina Target Diverse Plant Cell Compartments. Mol Plant-Microbe Interact. 2015;28(6):689-700,

5. Nyiko T, Kerenyi F, Szabadkai L, Benkovics AH, Major P, Sonkoly B, et al. Plant nonsense-mediated mRNA decay is controlled by different autoregulatory circuits and can be induced by an EJC-like complex. Nucleic Acids Res. 2013;41(13):6715-28.

6. Xu X, Pan S, Cheng S, Zhang B, Mu D, Ni P, et al. Genome sequence and analysis of the tuber crop potato. Nature. 2011;475(7355):189-95.

7. Kim S, Park M, Yeom SI, Kim YM, Lee JM, Lee HA, et al. Genome sequence of the hot pepper provides insights into the evolution of pungency in Capsicum species. Nat Genet. 2014:46(3):270-+.

8. Sato S, Tabata S, Hirakawa H, Asamizu E, Shirasawa K, Isobe S, et al. The tomato genome sequence provides insights into fleshy fruit evolution. Nature. 2012;485(7400):635-41.

9. Qin C, Yu CS, Shen YO, Fang XD, Chen L, Min JM, et al. Whole-genome sequencing of cultivated and wild peppers provides insights into Capsicum domestication and specialization. Proc Natl Acad Sci U S A. 2014;111(14):5135-40.

10. Sierro N, Battey JN, Ouadi S, Bovet L, Goepfert S, Bakaher N, et al. Reference genomes and transcriptomes of Nicotiana sylvestris and Nicotiana tomentosiformis. Genome Biol. 2013;14(6):R60.

11. Szittya G, Burgyan J. RNA interference-mediated intrinsic antiviral immunity in plants. Curr Top Microbiol Immunol. 2013;371:153-81.

12. Rogers K, Chen X. Biogenesis, turnover, and mode of action of plant microRNAs. Plant cell. 2013;25(7):2383-99.

13. Sun GL. MicroRNAs and their diverse functions in plants. Plant Mol Biol. 2012;80(1):17-36.

14. Sunkar R, Li YF, Jagadeeswaran G. Functions of microRNAs in plant stress responses. Trends Plant Sci. 2012;17(4):196-203.

15. Chavez Montes RA, de Fatima R-CF, De Paoli E, Accerbi M, Rymarquis LA, Mahalingam G, et al. Sample sequencing of vascular plants demonstrates widespread conservation and divergence of microRNAs. Nat Commun. 2014:5:3722

16. Cuperus JT, Fahlgren N, Carrington JC. Evolution and functional diversification of MIRNA genes. Plant cell. 2011;23(2):431-42.

17. Zhang B, Pan X, Cannon CH, Cobb GP, Anderson TA. Conservation and divergence of plant microRNA genes. Plant J Cell Mol Biol. 2006;46(2): 243-59.

18. Naim F, Nakasugi K, Crowhurst RN, Hilario E, Zwart AB, Hellens RP, et al. Advanced Engineering of Lipid Metabolism in Nicotiana benthamiana Using a Draft Genome and the V2 Viral Silencing-Suppressor Protein. PLoS One. 2012;7(12):e52717

19. Nakasugi K, Crowhurst RN, Bally J, Wood CC, Hellens RP, Waterhouse PM. De novo transcriptome sequence assembly and analysis of RNA silencing genes of Nicotiana benthamiana. PLoS One. 2013;8(3):e59534.

20. Nakasugi $K$, Crowhurst R, Bally J, Waterhouse P. Combining transcriptome assemblies from multiple de novo assemblers in the allo-tetraploid plant Nicotiana benthamiana. PLoS One. 2014;9(3):e91776.

21. Kawashima CG, Yoshimoto N, Maruyama-Nakashita A, Tsuchiya YN, Saito K, Takahashi $\mathrm{H}$, et al. Sulphur starvation induces the expression of microRNA395 and one of its target genes but in different cell types. Plant J Cell Mol Biol. 2009;57(2):313-21.

22. Fujii $\mathrm{H}$, Chiou TJ, Lin SI, Aung K, Zhu JK. A miRNA involved in phosphatestarvation response in Arabidopsis. Current Biol. 2005;15(22):2038-43.

23. Li F, Pignatta D, Bendix C, Brunkard JO, Cohn MM, Tung J, et al. MicroRNA regulation of plant innate immune receptors. Proc Natl Acad Sci U S A. 2012;109(5):1790-5.

24. Tang S, Wang Y, Li Z, Gui Y, Xiao B, Xie J, et al. Identification of wounding and topping responsive small RNAs in tobacco (Nicotiana tabacum). BMC Plant Biol. 2012;12:28.

25. Chen HM, Chen LT, Patel K, Li YH, Baulcombe DC, Wu SH. 22-Nucleotide RNAs trigger secondary siRNA biogenesis in plants. Proc Natl Acad Sci U S A. 2010;107(34):15269-74

26. Cuperus JT, Carbonell A, Fahlgren N, Garcia-Ruiz H, Burke RT, Takeda A, et al Unique functionality of 22-nt miRNAs in triggering RDR6-dependent siRNA 
biogenesis from target transcripts in Arabidopsis. Nat Struct Mol Biol. 2010; 17(8):997-1003.

27. Shivaprasad PV, Chen HM, Patel K, Bond DM, Santos BA, Baulcombe DC. A microRNA superfamily regulates nucleotide binding site-leucine-rich repeats and other mRNAs. Plant Cell. 2012;24(3):859-74.

28. Zhai JX, Jeong DH, De Paoli E, Park S, Rosen BD, Li YP, et al. MicroRNAs as master regulators of the plant NB-LRR defense gene family via the production of phased, trans-acting siRNAs. Gene Dev. 2011;25(23):2540-53.

29. Voinnet O. Origin, biogenesis, and activity of plant microRNAs. Cell. 2009; 136(4):669-87.

30. Mi SJ, Cai T, Hu YG, Chen Y, Hodges E, Ni FR, et al. Sorting of small RNAs into Arabidopsis argonaute complexes is directed by the 5 ' terminal nucleotide. Cell. 2008;133(1):116-27.

31. Hafner M, Renwick N, Brown M, Mihailovic A, Holoch D, Lin C, et al. RNAligase-dependent biases in miRNA representation in deep-sequenced small RNA cDNA libraries. RNA. 2011;17(9):1697-712.

32. Sorefan $\mathrm{K}$, Pais H, Hall AE, Kozomara A, Griffiths-Jones S, Moulton V, et al. Reducing ligation bias of small RNAs in libraries for next generation sequencing. Silence. 2012;3(1):4.

33. Sun GH, Wu XW, Wang JH, Li HQ, Li XJ, Gao HL, et al. A bias-reducing strategy in profiling small RNAs using Solexa. Rna-a Publication Rna Soc. 2011;17(12):2256-62.

34. Szittya G, Moxon S, Pantaleo V, Toth G, Rusholme Pilcher RL, Moulton V, et al. Structural and functional analysis of viral siRNAs. PLoS Pathog. 2010;6(4):e1000838.

35. Moxon S, Jing R, Szittya G, Schwach F, Rusholme Pilcher RL, Moulton V, et al. Deep sequencing of tomato short RNAs identifies microRNAs targeting genes involved in fruit ripening. Genome Res. 2008;18(10): 1602-9

36. Pantaleo V, Szittya G, Moxon S, Miozzi L, Moulton V, Dalmay T, et al. Identification of grapevine microRNAs and their targets using high-throughput sequencing and degradome analysis. Plant J. 2010;62(6):960-76.

37. German MA, Luo S, Schroth G, Meyers BC, Green PJ. Construction of Parallel Analysis of RNA Ends (PARE) libraries for the study of cleaved miRNA targets and the RNA degradome. Nat Protoc. 2009;4(3):356-62.

38. Addo-Quaye C, Eshoo TW, Bartel DP, Axtell MJ. Endogenous siRNA and miRNA targets identified by sequencing of the Arabidopsis degradome. Current Biol. 2008;18(10):758-62.

39. German MA, Pillay M, Jeong DH, Hetawal A, Luo S, Janardhanan $\mathrm{P}$, et al. Global identification of microRNA-target RNA pairs by parallel analysis of RNA ends. Nat Biotechnol. 2008;26(8):941-6.

40. Folkes L, Moxon S, Woolfenden HC, Stocks MB, Szittya G, Dalmay T, et al. PAREsnip: a tool for rapid genome-wide discovery of small RNA/target interactions evidenced through degradome sequencing. Nucleic Acids Res. 2012;40(13):e103.

41. Addo-Quaye C, Miller W, Axtell MJ. CleaveLand: a pipeline for using degradome data to find cleaved small RNA targets. Bioinformatics. 2009: 25(1):130-1.

42. Wang $Y$, Itaya A, Zhong $X H$, Wu Y, Zhang JF, van der Knaap E, et al. Function and Evolution of a MicroRNA That Regulates a Ca2 +-ATPase and Triggers the Formation of Phased Small Interfering RNAs in Tomato Reproductive Growth. Plant Cell. 2011;23(9):3185-203.

43. Pandey SP, Shahi P, Gase K, Baldwin IT. Herbivory-induced changes in the small-RNA transcriptome and phytohormone signaling in Nicotiana attenuata. Proc Natl Acad Sci U S A. 2008;105(12):4559-64.

44. Zhang H, Gao Z, Zheng X, Zhang Z. The role of G-proteins in plant immunity. Plant Signal Behav. 2012;7(10):1284-8.

45. Thung L, Trusov Y, Chakravorty D, Botella JR. Ggamma1 + Ggamma2 + Ggamma3 = Gbeta: the search for heterotrimeric $\mathrm{G}$-protein gamma subunits in Arabidopsis is over. J Plant Physiol. 2012;169(5):542-5.

46. Urano D, Chen JG, Botella JR, Jones AM. Heterotrimeric G protein signalling in the plant kingdom. Open Biology. 2013:3(3):120186.

47. Rasheed SA, Teo CR, Beillard EJ, Voorhoeve PM, Zhou W, Ghosh S, et al. MicroRNA-31 controls G protein alpha-13 (GNA13) expression and cell invasion in breast cancer cells. Mol Cancer. 2015;14:67.

48. Hu J, Baker A, Bartel B, Linka N, Mullen RT, Reumann S, et al. Plant peroxisomes: biogenesis and function. Plant Cell. 2012;24(6):2279-303.

49. Schumann U, Wanner G, Veenhuis M, Schmid M, Gietl C. AthPEX10, a nuclear gene essential for peroxisome and storage organelle formation during Arabidopsis embryogenesis. Proc Natl Acad Sci U S A. 2003;100(16): 9626-31.
50. Kamigaki A, Kondo M, Mano S, Hayashi M, Nishimura M. Suppression of peroxisome biogenesis factor 10 reduces cuticular wax accumulation by disrupting the ER network in Arabidopsis thaliana. Plant Cell Physiol. 2009; 50(12):2034-46.

51. Schumann U, Prestele J, O'Geen H, Brueggeman R, Wanner G, Gietl C. Requirement of the C3HC4 zinc RING finger of the Arabidopsis PEX10 for photorespiration and leaf peroxisome contact with chloroplasts. Proc Natl Acad Sci U S A. 2007:104(3):1069-74.

52. Morales-Ruiz T, Ortega-Galisteo AP, Ponferrada-Marin MI, Martinez-Macias MI, Ariza RR, Roldan-Arjona T. DEMETER and REPRESSOR OF SILENCING 1 encode 5-methylcytosine DNA glycosylases. Proc Natl Acad Sci U S A. 2006; 103(18):6853-8.

53. Law JA, Jacobsen SE. Establishing, maintaining and modifying DNA methylation patterns in plants and animals. Nat Rev Genet. 2010;11(3):204-20

54. Li Q, Wang X, Sun H, Zeng J, Cao Z, Li Y, et al. Regulation of Active DNA Demethylation by a Methyl-CpG-Binding Domain Protein in Arabidopsis thaliana. PLoS Genet. 2015:11(5):e1005210.

55. Williams BP, Pignatta D, Henikoff S, Gehring M. Methylation-sensitive expression of a DNA demethylase gene serves as an epigenetic rheostat. PLoS Genet. 2015;11(3):e1005142.

56. Sunkar R, Zhu JK. Novel and stress-regulated microRNAs and other small RNAs from Arabidopsis. Plant Cell. 2004;16(8):2001-19.

57. Kim JY, Kwak KJ, Jung HJ, Lee HJ, Kang H. MicroRNA402 affects seed germination of Arabidopsis thaliana under stress conditions via targeting DEMETER-LIKE Protein3 mRNA. Plant Cell Physiol. 2010;51(6):1079-83.

58. Li S, Zhou X, Huang Y, Zhu L, Zhang S, Zhao Y, et al. Identification and characterization of the zinc-regulated transporters, iron-regulated transporterlike protein (ZIP) gene family in maize. BMC Plant Biol. 2013;13:114.

59. Paul S, Datta SK, Datta K. miRNA regulation of nutrient homeostasis in plants. Frontiers Plant Sci. 2015;6:232.

60. Szittya G, Salamon P, Burgyan J. The complete nucleotide sequence and synthesis of infectious RNA of genomic and defective interfering RNAs of TBSV-P. Virus Res. 2000;69(2):131-6.

61. Pall GS, Hamilton AJ. Improved northern blot method for enhanced detection of small RNA. Nat Protoc. 2008;3(6):1077-84.

62. Chen C, Ridzon DA, Broomer AJ, Zhou Z, Lee DH, Nguyen JT, et al. Realtime quantification of microRNAs by stem-loop RT-PCR. Nucleic Acids Res. 2005;33(20):e179.

63. Turner M, Adhikari S, Subramanian S: Optimizing stem-loop qPCR assays through multiplexed cDNA synthesis of U6 and miRNAs. Plant Sign Behavior 2013, 8(8) doi: 10.4161/psb.24918.

64. Varkonyi-Gasic E, Wu R, Wood M, Walton EF, Hellens RP. Protocol: a highly sensitive RT-PCR method for detection and quantification of microRNAs. Plant Methods. 2007;3:12

65. Martin M: Cutadapt removes adapter sequences from high-throughput sequencing reads. EMBnet J. 2011;17:10-12.

66. Stocks MB, Moxon S, Mapleson D, Woolfenden HC, Mohorianu I, Folkes L, et al. The UEA sRNA workbench: a suite of tools for analysing and visualizing next generation sequencing microRNA and small RNA datasets. Bioinformatics. 2012;28(15):2059-61.

67. R Development Core Team: R: A Language and Environment for Statistical Computing. In. Vienna, Austria: R Foundation for Statistical Computing; 2014.

68. Grabherr MG, Haas BJ, Yassour M, Levin JZ, Thompson DA, Amit I, et al. Fulllength transcriptome assembly from RNA-Seq data without a reference genome. Nat Biotechnol. 2011:29(7):644-U130.

69. Du Z, Zhou X, Ling Y, Zhang Z, Su Z. agriGO: a GO analysis toolkit for the agricultural community. Nucleic Acids Res. 2010;38(Web Server issue):W64-70. 